\title{
LA CHIESA DI S. SOFIA DI COSTANTINOPOLI NELLA DESCRIZIONE DI PROCOPIO DI CESAREA
}

\author{
Eleonora Vitale* \\ Università degli Studi di Napoli Federico II
}

Resumo. La Chiesa di Santa Sofia di Costantinopoli, voluta da Costantino e restaurata dai successive imperatori, fu il simbolo della politica imperiale di Giustiniano: distrutta da un incendio appiccato nel Palazzo del Senato (532) durante la rivolta "Nika", fu ricostruita magnificamente dall'imperatore che volle mostrare la vittoria contro i suoi avversari politici e lodare la vittoria dell'ortodossia. La Grande Chiesa dell'imperatore è descritta nel primo libro dell'opera De aedificiis di Procopio di Cesarea, che intende glorificare Giustiniano, il sovrano-costruttore, protetto da Dio, attraverso il catalogo degli edifici approvati da lui nell'impero terreno, imitanti la sacralità e la magnificenza del regno celeste. Prendendo nel dettaglio alcuni brani, l'analisi intenderà correlarli ad alcune immagini della Chiesa di Santa Sofia (piantine, immagini), mettendo in evidenza la cura particolare dell'autore nel sottolineare l'uso di materiali e nel descrivere la struttura della chiesa nel dettaglio. Sembra che egli voglia evidenziare che questi conducono a Dio perché permettono di notare, al di là dei materiali, significati simbolici e perché, la contemplazione della bellezza dell'edificio voluto dall'imperatore da Lui scelto, risulta essere essa stessa una preghiera di lode. Ma soprattutto l'intervento cercherà di dimostrare che, sebbene le sezioni descrittive siano accurate e numerose, la trattazione dello storico, di cui già alcuni studiosi hanno sottolineato l'atteggiamento e il linguaggio di retore, non è solo un' éк $\varphi$ paбıৎ della chiesa, ma un tributo encomiastico a Giustiniano, e che la matrice retorica del testo è evidente soprattutto nella lode dell'ingegno e della durevole applicabilità pratica degli atti dell'imperatore ispirato da Dio. Palavras-chave. Procopio di Cesarea; Santa Sofia; Giustiniano; retorica; descrizione. D.O.I. 10.11606/issn.2358-3150.v19i1p3-42

LA CITTÀ DI BISANZIO NEL VI SECOLO D.C. ${ }^{1}$ ERA CARATTERIZZATA DA UN'ARchitettura fastosa, arricchita da Giustiniano sì da renderla degna dell'importanza di centro culturale che essa andava assumendo. Il cuore della città

\footnotetext{
* Graduated at Università degli Studi di Napoli Federico II.

* Artigo recebido em 27.out.2015 e aceito para publicação em 15.jan.2016.

${ }^{1}$ Nonostante la città, dalla rifondazione costantiniana (330 d.C.), venne chiamata Costantinopoli in onore dell'imperatore (e questo nome usato a partire dal IV secolo), il toponimo Bisanzio è preferito da Procopio (Cameron 1985, 102) nel De aedificiis, ed è preferito per sottolineare il carattere romano degli abitanti della città che, invece, non possedevano i barbari, estranei alla Rhomania "terra dei Romani", da essa esclusi. Fra il molto relativo alla città di Bisanzio nel VI secolo i contributi più recenti sono: Brehier 2009, Janin 1964, Kashdan 1995, Norwich 2000.
} 
si trovava proteso verso il mare, sul sito greco-romano. Da qui si dipartiva la principale arteria della città, la Mese, "via centrale", che, in corrispondenza della piazza del Philopation $^{2}$ si diramava ad $\mathrm{Y}$. Un ramo proseguiva verso nord, in direzione della porta di Adrianopoli e della via che conduceva al cuore dei Balcani, l'altro proseguiva invece verso sud-est, trasformandosi nella via Trionfale che, raggiungendo la Porta d'oro, ${ }^{3}$ conduceva alla via Egnazia, in direzione della Grecia e di Roma. Il porto principale era presso il palazzo imperiale edificato sull'estremità meridionale della penisola. Fra le strutture che la città aveva ereditato dal primo imperatore, degno esempio era $\mathrm{l}^{\prime}$ Ippodromo, ${ }^{4}$ costruito con priorità assoluta assieme alle mura e ispirato al Circo Massimo di Roma; esso era straordinariamente monumentale e capiente, con una lunghezza di circa $450 \mathrm{~m}$ per $120 \mathrm{~m}$ di larghezza. La sua importanza era dovuta soprattutto quale luogo deputato all' "epifania" imperiale, cioè all'apparizione del sovrano nella sua tribuna, dalla quale si mostrava al popolo per presenziare ai giochi, circondato da segni di regalità e potere che dovevano apparire quasi ultraterreni, nell'acclamazione rituale della folla. L'Ippodromo era anche il fulcro di collegamento tra la zona imperiale a sud, e i nuovi quartieri residenziali a nord.

Il foro, che si trovava ad occidente, su un'altura, era a pianta circolare e circondato da colonne a doppio ordine. Al centro del foro si trovava la colonna-santuario, sormontata da una statua bronzea dell'Imperatore rappresentato come Helios; la colonna si ergeva su uno zoccolo alto circa cinque metri, che racchiudeva un santuario dove, già al tempo di Costantino, si celebravano cerimonie, si bruciavano incensi, si accendevano lampade votive e si pregava, verso l'immagine imperiale, affinché scongiurasse sciagure e proteggesse la città che aveva fondato. Tra le chiese più importanti nella città nel vi secolo d.C. fondate da Costantino, c'erano quella dedicata alla Santa Sapienza, Santa Sofia, prima della riedificazione al tempo di Giustiniano, destinata a diventare cattedrale, e quella dei Santi Apostoli, a pianta centrale, che divenne il mausoleo imperiale. Si poteva ammirare il milion, un arco considerato il "centro" dell'Impero, dal quale si misuravano le distanze con le altre città, a nord del nucleo centrale palatino la Magnaura (dal lat. magna aula), una sala di rappresentanza attribuita a Costantino I, dove venivano svolti gli atti solenni e ricevute le ambascerie più importanti, e il Palazzo del Boukoleon, residenza privata degli imperatori,

\footnotetext{
${ }^{2}$ Palazzo al di fuori delle mura della città, considerata residenza primaverile e estiva preferita da Giustiniano e da Teodora .

${ }^{3}$ Porta principale che attraversava le mura cittadine, originariamente arco trionfale costruito nel 388 da Teodosio I (347-395) per celebrare la vittoria su Magno Massimo. Cfr. Turnball 2009.

${ }^{4}$ Cfr. Vespignani 2001.
} 
il quale sotto Giustiniano assunse tale nome in seguito a modifiche che avevano reso fastoso l'interno. Durante il suo regno, inoltre, Giustiniano fece anche costruire la chiesa di S. Irene e quella dei Santi Sergio e Bacco, nella quale restano capitelli e architravi decorati con un fitto traforo vegetale, preferendo gli edifici a pianta centrale, al fine di esprimere appieno la grandezza del suo regno.

\section{L'ASCESA AL POTERE DI GIUSTINIANO E LE RIFORME ECCLESIASTICHE}

Giustiniano $^{5}$ (11 maggio 482 d.C. -14 novembre 565 d.C.), parven $u^{6}$ della cultura romana d'Oriente si era trasferito grazie allo zio Giustino ( $450-527$ d.C.) nella capitale dal nativo villaggio macedone, Tauresio, vicino al confine albanese $\mathrm{e}^{7}$ ed era di stirpe illirica, la stessa che aveva dato a Roma nel passato molti altri grandi imperatori fra i quali Costantino il Grande (274-337 d.C.). La sua ascesa al potere fu dovuta a fortuna e ad una buona dose di versatilità politica. Durante il regno di Leone II (467-474 d.C.), Giustino e due altri giovani illiri, tre agricoltori, che erano stati probabilmente ridotti in povertà da una nuova incursione di Unni in Macedonia, migrarono a Costantinopoli; grazie alla loro prestanza fisica furono arruolati dall'imperatore nel corpo degli Excubitores, ${ }^{8}$ guardie di palazzo che egli stava organizzando per controbilanciare l'eccessiva influenza dei Germani presenti nell'esercito imperiale. La storia non conosce molto dei due compagni ma, fra i tre, Giustino crebbe in perizia militare fino a diventare comandante della guardia sotto l'imperatore Anastasio ${ }^{9}$ (430-518 d.C.) dopo ben cinquant'anni di carriera militare. Anastasio morì nel 518, forse all'età di 90 anni, non lasciando alcuna disposizione per il suo successore e i suoi tre nipoti non erano ritenuti degni candidati al trono.

Uno dei suoi principali ministri diede a Giustino una grossa somma di denaro da usare come donativo per incoraggiare il sostegno fra le truppe a favore di un suo candidato, ma Giustino la usò per suoi propositi, divenendo egli stesso imperatore.

${ }^{5}$ Sull'imperatore Giustiniano I tra il molto si confronti tra i contributi più recenti: Atkinson 2000, Capizzi 1994, Evans 1996, Maraval 1999, Mazal 2001, Meier 2004, Ravegnani 2008, 37-50.

${ }^{6}$ La definizione è di Brown 1974.

7 Proc., Aed. 1.17-27.

${ }^{8}$ Cfr. Evans 1970, 217; Jones 1981, 281, 333, 388, 897 ss.

${ }^{9}$ Proc., Anec. 6.1-11. 
Era incolto, quasi ottantenne quando salì al trono ma comprese l'importanza di dividere con la propria famiglia il capitale accumulato e di portare almeno due dei suoi nipoti da Tauresio a Costantinopoli così da curarne l'istruzione..$^{10}$ Uno di questi, Flavio Pietro Sabbazio Giustiniano, figlio di una sua sorella e da lui adottato come figlio, si distinse subito, dapprima come braccio destro dell'imperatore e poi, alla morte dello stesso, come suo successore al trono. ${ }^{11} \mathrm{Al}$ momento dell'avvento al trono di Giustino, Giustiniano era un candidatus, uno dei quarantacinque ufficiali (detti così dalla loro uniforme bianca) delle scholae palatinae, la guardia del corpo personale del sovrano. Nel 521 d.C. divenne magister militum praesentialis, comandante di uno degli eserciti campali di stanza nella capitale, e ottenne la dignità di console; nel 526 d.C. assunse il titolo di patrizio e di nobilissimo e il 4 aprile 527 d.C. Giustino lo associò al trono con il rango di Augusto. ${ }^{12}$ Già durante il regno dello zio pare che il futuro imperatore abbia notato come il latino, lingua dell'amministrazione, della giustizia e dell'esercito fosse scarsamente conosciuto dai cittadini delle province orientali, dove le principali lingue d'uso erano il greco, il copto (in Egitto), l'aramaico (in Siria) e l'armeno (in Asia Minore); d'altronde egli fu forse l'ultimo imperatore a poter affermare che questa era la sua lingua nativa. ${ }^{13}$

A Costantinopoli acquistò una conoscenza profonda della letteratura teologica greca e optò per il partito monofisita ${ }^{14}$ ponendo fine allo scisma fra Roma e Bisanzio che durava dal 483 d.C.; frequentò il demimonde; giocò alla politica con le fazioni del circo $^{15}$ e scelse come sua sposa Teodora, ${ }^{16}$

${ }^{10}$ Per un approfondimento sugli studi e l'adozione di Giustiniano: cfr. Browning 1986, 165-78.

${ }^{11}$ Nonostante sulla base di alcuni resoconti di Procopio di Cesarea si è ritenuto avesse governato a nome dello zio già dal 518, anno dell'ascesa al trono di Giustino, che sarebbe stato troppo anziano per governare. Cfr. Mooread 1994, 21-2 con un riferimento a Proc., Anec. 8.3.

${ }^{12}$ Ravegnani, 2008a, 54.

${ }_{13}$ Secondo quanto ritiene Evans 1970, 217.

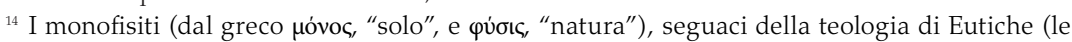
cui dottrine vennero condannate come eretiche nel concilio di Calcedonia nel 451) attribuivano a Cristo la sola natura divina che aveva assorbito quella umana. Cfr. Enciclopedia Cattolica VIII, Città del Vaticano 1952, pp. 1299-1302; Padovese 1993, 676-7. Giustiniano sembrò orientarsi verso un monofisismo di tipo aftartodocetistico che giungeva a postulare l'incorruttibilità del corpo di Cristo anche prima della Resurrezione.

${ }^{15}$ Le due principali fazioni erano quella dei Verdi ("dei contribuenti", cui aderirono i monofisiti e i due nipoti di Anastasio) e quella degli Azzurri ("dei miserabili", sostenuta dalla coppia imperiale). Cfr. Ravegnani 2008a, 17-18: "Nella tarda antichità l'ostacolo più serio all'assolutismo fu rappresentato dai 'demi' o 'partiti del circo' che gravitavano intorno all'ippodromo della capitale. Nati come associazione sportiva, sul modello romano, i demi assunsero fra il IV e il V secolo anche una fisionomia politica che avrebbero poi mantenuto fino al VII secolo."

${ }^{16}$ Giustiniano aveva potuto sposare Teodora, una ex attrice di mimo, grazie all'abrogazione (525 d.C.) da parte di Giustino, di una legge che proibiva ai membri della classe senatoriale di sposare una donna di classe sociale inferiore, comprese le attrici di teatro, che all'epoca erano considerate scandalose. Cfr. Procopio Di Cesarea, Anec. 6. Fra l'altro lo stesso zio dell'imperatore 
appartenente ad una famiglia legata alle scuderie da corsa. ${ }^{17}$ Fin da giovane si sforzò di adeguarsi alla politica retrograda dell'aristocrazia locale corteggiando i senatori di Costantinopoli e quando divenne console, dedicò loro con umiltà alcuni suoi dittici in latino.

Quando salì al trono ( 1 agosto 527 d.C.) gli anni che si aprivano davanti a lui erano di cambiamento (il suo primo atto da imperatore fu l'istituzione di una commissione di revisione del diritto romano) e di conflittualità interna rappresentata dalla rivolta "Nika" ( 11 gennaio 532 d.C.) ${ }^{18}$ nel momento in cui le due fazioni dell'ippodromo degli Azzurri e dei Verdi si scontrarono l'una contro l'altra fino a creare un clima di omicidi e delitti a danno soprattutto dei Verdi, sostenuti dalla coppia imperiale.

Il giorno 13 gennaio durante le corse dei carri, i rappresentanti delle due fazioni chiesero invano la grazia per due loro membri, condannati per motivi di ordine pubblico, e il rifiuto di concederla da parte del sovrano fu il segnale della sollevazione. In occasione della rivolta, l'imperatore si era chiuso nel suo palazzo e, dopo cinque giorni, i rivoltosi non esitarono a bruciare l'edificio della prefettura (dove si trovavano le prigioni), a forzare i cancelli del palazzo e a bruciarne il vestibolo, la chiesa di S. Sofia e altre costruzioni nelle vicinanze. Nonostante la promessa di una riduzione delle tasse e di sanzioni ai capi di entrambe le fazioni, i moti popolari si trascinarono fino al giorno 18 quando la folla chiese la destituzione dell'imperatore in favore del nipote di Anastasio I, Ipazio.

Mentre le fiamme si levavano intorno al palazzo, la sola Teodora fu in grado di infondere coraggio al marito colto dal panico e deciso ad abbandonare la capitale, dicendogli che "la porpora è un sudario glorioso". ${ }^{19}$ Grazie all'intervento di Narsete e di Belisario si riuscì a porre fine a questa drammatica parentesi dei primi anni di regno di Giustiniano: il primo diede agli Azzurri metà della somma che lo stesso imperatore aveva fatto caricare su una nave per fuggire, così che i rivoltosi di entrambe le fazioni si riunirono nell'Ippodromo dove, con l'aiuto del secondo, furono uccise 35.000 persone.

aveva sposato un ex schiava Lupicina che, divenuta sovrana, aveva mutato il suo nome in Eufemia. La legge venne poi posta da Giustiniano nel Codex (5.4.23 = p.119 Kruger), tant'è che gli storici sono concordi nel ritenere si tratti di una legge giustinianea.

${ }^{17}$ Il padre di Teodora, legato alla fazione dei Verdi, era il guardiano degli orsi all'ippodromo, la madre una danzatrice che recitava anche in spettacoli osceni. Secondo Procopio ella era stata convertita ad Alessandria ad opera del patriarca Timoteo, che ne aveva fatto un ardente monofisita. Cfr. Proc., Anec. 6.

${ }^{18}$ La rivolta "Nika" trae il suo nome dalla parola d'ordine dei congiurati (víka, "vinci"), grido con cui il popolo era solito incitare i propri campioni all'interno dell'ippodromo nelle corse dei carri. La folla tentò di rovesciare l'imperatore che dopo pochi giorni spense la ribellione nel sangue. Cfr. Meier 2003, 273-300.

${ }_{19}$ Proc., Storia delle guerre persiane 1.24, trad. a cura di F. Conca e P. Cesaretti, Milano 1996. 
Ipazio venne condannato a morte insieme al fratello Pompeo, mentre diciotto senatori subirono l'esilio e la confisca dei beni, per essere poi richiamati e reintegrati nei loro diritti qualche tempo dopo. Questa rivolta mutò in modo drammatico il ritmo del suo regno. In seguito Giustiniano volse le spalle agli elementi tradizionali della città. Sfruttò, come nessun altro imperatore romano d'Oriente aveva mai fatto, le risorse dell'autocrazia: le cerimonie tradizionali furono messe da parte per lasciare spazio alla sola figura dell'imperatore che abolì nel 541 d.C. anche la carica di console, da lui apprezzata da giovane. La vita di corte divenne più fastosa e il cerimoniale più solenne tanto che l'imperatrice viaggiava con un seguito di 4000 persone (un numero superiore, pare, a quello del seguito del sultano ottomano del xIX secolo) e il rito dell'adorazione venne esteso anche ai senatori, che fino a quel momento ne erano stati esenti. Come per l'amministrazione secolare, il dispotismo apparve anche nella politica ecclesiastica dell'imperatore. Egli regolava tutto, sia nella legge che nella religione.

La politica religiosa di Giustiniano ${ }^{20}$ infatti, rifletteva la convinzione imperiale che l'unità dell'impero presupponesse incondizionatamente l'unità della fede, e con lui sembrò un dato di fatto che questa fede potesse essere solo l'ortodossia. Agli inizi del suo regno (527 d.C. c.a.), ritenne appropriato promulgare per legge il suo credo nella Trinità e nell'Incarnazione, negando, quindi, la sua giovanile propensione al monofisismo, minacciare tutti gli eretici con delle punizioni ${ }^{21}$ con la sola eccezione dei Goti che militavano nell'esercito, ai quali fu consentito di praticare il culto ariano, privare tutti i disturbatori dell'ortodossia dell'opportunità, per tale offesa, di subire un giusto processo di legge. Contro i Samaritani, gruppo etnico religioso avversato da cristiani e ebrei, vennero emessi editti che impedivano loro di possedere proprietà.

Inoltre a Samaritani, Ebrei e pagani fu vietato di ereditare o fare testamento e donazioni se non in favore di cattolici. A tutti coloro che non seguivano il credo cristiano, compresi gli Ebrei, fu impedito di testimoniare in tribunale contro i cattolici o possedere schiavi cattolici; anche contro i Manichei vennero comminati esili e pene capitali, ${ }^{22}$ che vennero estesi anche a chi, pur avendo ricevuto il battesimo, continuasse a praticare riti pagani. ${ }^{23}$ L'esecuzione dei provvedimenti legislativi venne affidata ai vescovi e alle autorità laiche e, per renderli ancora più drastici, si ingiunse anche di sottrarre i figli alle famiglie non del tutto convertite affinché ricevessero

${ }^{20}$ Cfr. Capizzi 1994, 353-63.

${ }^{21}$ Cod. Just. $1 \cdot 1 \cdot 5=$ p. $35-6$ Kruger.

${ }^{22}$ Cod. Just. $1.5 \cdot 12=$ p. 35 Kruger.

${ }^{23}$ Cfr. Ravegnani 2008b, 48-50. 
un'istruzione cristiana. Ma contro le minoranze isolate di pagani ancora esistenti, la repressione della dissidenza religiosa non fu soltanto legislativa e si ebbero frequenti persecuzioni, tanto che nel 533 d.C. organizzò crociate contro i regni che seguivano l'eresia di Ario $^{24}$ in Occidente, Samaritani ${ }^{25}$ e montanisti, ${ }^{26}$ una setta eretica diffusa in Frigia. Sancì l'interdizione dei pagani $^{27}$ e degli eretici dall'insegnamento dando vita ad una svolta decisiva nell'evoluzione dell'insegnamento superiore: coloro che non seguivano "la Chiesa cattolica e apostolica e la fede ortodossa", eretici, giudei, pagani, non potevano "sotto la specie di qualunque forma d'insegnamento attirare ai loro errori anime semplici", ${ }^{28}$ e compiendo un passo decisivo verso l'accentramento della cultura nella capitale.

L'insegnamento del diritto fu limitato alle scuole di Bisanzio, Berìto e Roma, anche se le scuole di queste ultime due città ben presto decaddero

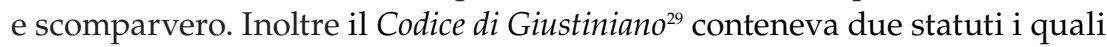
decretavano la totale distruzione dell'Ellenismo anche nella vita civile: "Proibiamo che un qualche insegnamento possa essere professato da coloro che sono malati della follia sacrilega degli Elleni" ${ }^{\prime \prime 30}$ e queste disposizioni vennero attuate con zelo. Si ordinò, infatti, la chiusura o la distruzione degli ultimi templi ancora in funzione e migliaia di pagani in Asia Minore vennero costretti a convertirsi con la forza. La vittima più illustre delle persecuzioni giustinianee fu l'Accademia platonica di Atene, simbolo culturale e identitario della cultura ellenica, tradizionale rifugio della cultura pagana, tacitamente tollerata dagli imperatori, che venne chiusa nel 529 d.C. costrin-

\footnotetext{
${ }^{24}$ Per comprendere le dottrine teologiche di Ario è necessario distinguere fra ariani estremisti (o anomèi), semi-ariani e moderati. I primi comprendono lo stesso Ario e i suoi seguaci, e riten-

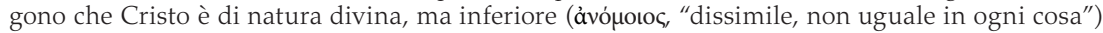
in quanto creato da Dio. Sono anche detti aeziani (in quanto seguaci di Aezio di Antiochia) e eunomiani (in quanto aderì a tale corrente di pensiero Eunomio di Cizico). I secondi comprendono, invece, gli omoeusiani i quali ritengono il Verbo semplicemente simile al Padre in quanto simile alla sua essenza (ónoเov́øıc). Questi, seguaci di Basilio di Ancira, sono detti semi-ariani in quanto non pochi di loro si compromisero riconoscendo la vera divinità del Figlio ma negando la divinità dello Spirito Santo. I terzi comprendevano uomini dalla dottrina moderata come l'imperatore Costanzo II che ritenevano che la natura del Figlio era simile (ö $\mu$ otoc, "simile, non uguale"), ma non uguale a quella del Padre. Cfr. Enciclopedia Cattolica I, pp. 1883-5.

${ }^{25}$ Già sotto Giustino nel 529 era scoppiata una rivolta samaritana repressa nel sangue e nel 556 un'altra rivolta di Samaritani e alleati ebrei finì grazie alla dura repressione giustinianea anche se alla fine del regno di Giustiniano molte furono le ritorsioni contro i cristiani da parte di questo popolo. Cfr. Ravegnani 2008b, 47.

${ }^{26}$ Cfr. Enciclopedia cattolica X, pp. 1522-3.

${ }^{27}$ Cfr. Ravegnani, 2008b, 48: "Particolarmente severa fu la legislazione antipagana che (...) impose ai rei l'obbligo di essere istruiti nella religione cristiana e di ricevere il battesimo, pena l'esilio e la confisca dei beni."

${ }^{28}$ Cod. Just. 1.5.18.4 = p. 36 Kruger (trad. di Impellizzeri 1975, 29).

${ }^{29}$ Cfr. Archi 1970; Nardi 1991; Luchetti 2004.

${ }^{30}$ Cod. Just. 1.11 .10 (i due statuti citati sono questo e il precedente)= p. 41 Kruger.
} 
gendo i professori non disposti a convertirsi a fuggire nel regno persiano. L'avvenimento è importante anche come elemento di periodizzazione: è infatti uno dei simboli principali della fine del mondo antico, la cui religione tradizionale viene definitivamente sconfitta dal cristianesimo anche se per qualche tempo ancora si ebbero sporadiche sopravvivenze di paganesimo.

Le fonti contemporanee (Giovanni Malala, Teofane Confessore, Giovanni di Efeso) ${ }^{31}$ ci parlano di gravi persecuzioni di uomini altolocati e dignitari di corte e diversi vescovi dovettero subire l'ira dell'imperatore a partire dal 527, anche se nuove persecuzioni ebbero luogo fra il 545 e il 546 d.C. soprattutto contro esponenti della aristocrazia e della cultura. Giustiniano

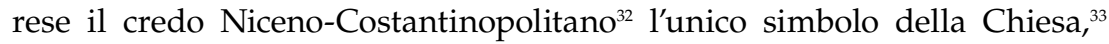
e concesse valore legale ai canoni dei quattro concili ecumenici. I vescovi partecipanti al secondo concilio di Costantinopoli del 553 d.C., sancirono che nella Chiesa non poteva essere fatto niente in contrasto alla volontà e agli ordini dell'imperatore. Il riconoscimento della sede romana come la più alta autorità ecclesiastica, ${ }^{34}$ rimase, d'altra parte, la chiave di volta della sua politica occidentale, nonostante in Oriente suonasse offensiva a molti. Egli, però, si sentì completamente libero di prendere posizioni dispotiche nei confronti del Papa; si ricordi l'imprigionamento di Vigilio nel 548 d.C. (nonostante, nella nomina a papa, fosse stato appoggiato dall'imperatrice), per il suo rifiuto a legittimare $\mathrm{l}^{\prime}$ Editto dei tre capitoli in condanna ad alcune opere teologiche. Mentre nessun compromesso poteva essere accettato dall'ala dogmatica della Chiesa, i suoi sforzi sinceri di riconciliazione gli fecero ottenere l'approvazione della maggior parte della Chiesa. Nella condanna dei

\footnotetext{
${ }^{31}$ Giovanni Malala, dal siriaco malâlâ ("retore") scrisse le Cronografie, che va dall'origine del mondo a Giustiniano, di cui ci restano 18 libri. L'autore, autore siriaco probabilmente di Antiochia, dà origine ad un'opera che si distingue per lo schema annalistico e in cui indulge al meraviglioso e al fantastico prestando poca attenzione a eventi di grande portata. Per un confronto con Procopio di Cesarea si veda, tra i più recenti contributi, Jeffreys 2000. Teofane Confessore (o Isauro) scrisse una Cronaca che narrava gli eventi dal 284 al 813 dedicando ogni capitolo a un anno della storia dell'impero (anni domini o anni mundi). Cfr. Mango 2006, 68 ss. Giovanni di Efeso scrisse una Storia della chiesa in siriaco che narrava gli eventi da Giulio Cesare all'anno 588. Cfr. Kraft, Gulzow \& Werz 1976, 193 ss.

${ }^{32}$ Il simbolo niceno, approvato nel concilio di Nicea (325 d.C.) era una formula di fede relativa all'unicità di Dio e alla natura di Gesù: "Il Figlio di Dio è della sostanza del Padre, consustanziale

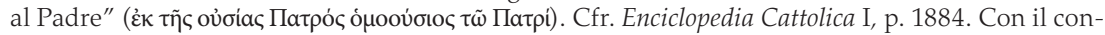
cilio di Costantinopoli (381 d.C.), si stabilì la formula del simbolo niceno- costantinopolitano relativo alla natura dello Spirito Santo. Oltre al contenuto del simbolo niceno contiene la novità del cuius regni non erit finis, parole bibliche $(L C .1,33)$ e gli attributi allo Spirito Santo: Dominum (che ha il valore di servo per essenza) et vivificantem (che indica che ha la vita in sé e che è esso stesso sorgente di vita) qui ex Patre procedit (che sembra essere contro i macedoniani per cui lo Spirito è creatura del Figlio), qui cum Patre et Filio simul adoratur et glorificatur (se lo Spirito Santo è pari al Padre e al Figlio è di natura divina). Cfr. Enciclopedia Cattolica IV, p. 746.

${ }^{33}$ Cod. Just. 50.1 .17 = p. 920-26 Kruger.

${ }^{34}$ Nov. XLII = pp. 263-9 Schoell- Kroll.
} 
tre capitoli ${ }^{35}$ Giustiniano cercò di conciliare Oriente e Occidente, ma senza risultato. Anche se il Papa acconsentì alla condanna dei tre capitoli, l'Occidente credeva che l'imperatore avesse agito in maniera contraria ai decreti di Calcedonia (451 d.C.); e anche se molti delegati ad Oriente risultarono asserviti a Giustiniano, molti altri, specialmente i monofisiti, rimasero insoddisfatti. Così l'imperatore sprecò i suoi sforzi per un compito impossibile, il più amaro per lui che, durante i suoi ultimi anni, ebbe grande interesse per le questioni teologiche. A lode della grandezza della Chiesa orientale, fece costruire edifici sacri nello stile delle chiese della capitale e fece in modo che, grazie ad atti memorabili di carità cristiana e di cristiana tolleranza, con il denaro, i mosaici e l'attività edilizia, la figura dell'autocrate, fosse sotto gli occhi di tutti. Solo successivamente ci si rese conto dei gravi danni che tale autocrazia di Giustiniano provocò: l'indebolimento del fondamento aristocratico della cultura tardo-antica; il deterioramento della burocrazia tradizionale a causa del governo personalistico; l'esaurimento della vita delle provincie a causa dell'accentramento amministrativo. Di conseguenza alla fine del vi secolo d.C. la cultura della classe dominante coincise con la cultura cristiana dell'uomo medio. Sia il Codex sia le Novellae ${ }^{36}$ contengono molti decreti riguardanti donazioni, fondazioni, e l'amministrazione della proprietà ecclesiastica; elezioni e diritti di vescovi, sacerdoti ed abati; vita monastica (anche se l'imperatore non favorì molto il monachesimo), obblighi residenziali del clero, condotta del servizio divino, giurisdizione episcopale. A Bisanzio l'imperatore tracciò una triplice distinzione riguardo alla organizzazione della vita ecclesiastica della città. ${ }^{37}$ Vi era la Grande Chiesa comprendente quattro chiese, S. Sofia, S. Elena, S. Teodoro (costruita da Sporacio nel 452 d.C.), e la chiesa della Beata Vergine (costruita per volere di Elia Verina), ${ }^{38}$ amministrata come una singola unità e servita da un solo corpo di chierici; le chiese "il cui mantenimento era assunto dalla Grande Chiesa" che avevano i loro corpi separati di chierici; e "le chiese che non ricevono il mantenimento della Grande Chiesa". ${ }^{39}$ Le chiese della città tendevano a essere "tituli" sia perché erano state costruite dal vescovo con i fondi centrali o

\footnotetext{
${ }^{35}$ Giustiniano dichiarò eretici la persona e le opere di Teodoro di Mopsuestia, Teodoreto di Cirro, e la lettera di Iba di Edessa in difesa di Teodoro: tutti e tre erano appartenenti alla scuola di Antiochia e già morti. La sua condanna fu considerata eccessiva nella difesa della duplice natura

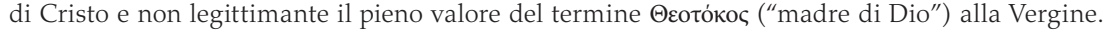
Inoltre l'imperatore convocò un concilio il 5 maggio 553 a Costantinopoli e papa Vigilio, all'inizio reticente a firmare la condanna, dopo un periodo di prigionia, si convinse (8 dicembre 553). Cfr. Enciclopedia Cattolica IV, pp. 747-8.

${ }^{36}$ Cfr. Pescani 1965.

${ }^{37}$ Cfr. Jones 1981, 366-9.

${ }^{38}$ Elia Verina fu la moglie dell'imperatore Leone I (417-474), suocera di Zenone.

${ }^{39}$ Jones 1981, 932 ss.
} 
con una sottoscrizione, sia perché erano state amalgamate. Una prova della volontà di Giustiniano di voler accentrare egli stesso, proprio nella capitale, il centro del culto cristiano- orientale, è nell'uso della sua ricchezza per la ricostruzione della chiesa di Haghia Sophia, il cui sito originario era stato distrutto durante la rivolta Nika. ${ }^{40}$ La nuova Haghia Sophia con le sue numerose cappelle e sacrari, la cupola ottagonale dorata, e i mosaici divenne il centro e il monumento più visibile dell'ortodossia Orientale a Costantinopoli, tanto importante nella politica religiosa di Giustiniano.

\section{S. SOFIA, LA “GRANDE CHIESA” DELL'IMPERATORE.}

Il tempio della Divina Sapienza ("Aүı Sopí) fu veramente il simbolo della politica imperiale. Era nello spirito dei tempi, minacciati da una presentita crisi, raccogliere la varietà delle esperienze nell'unità di un simbolo, tanto più efficace, quanto più straordinario per la sua costruzione. Nello splendore della sua forza espressiva il tempio di S. Sofia fu in grado di ottenere energie e capacità insospettate e di offrire motivi di conforto e di fiducia. Oltre che per il mirabile fascino della sua bellezza, la chiesa si prestò, per la storia stessa della sua creazione, ad essere testimonianza incarnata degli eventi giustinianei. ${ }^{41}$ Costruita per volere di Costantino su un sito occupato originariamente da templi pagani, la chiesa fu consacrata alla Divina Sapienza ${ }^{42}$ dal patriarca Eudossio ( 15 febbraio 360 d.C.) durante il regno di Costanzo II (337-361); di questa primitiva costruzione ancora sussiste un piccolo edificio circolare laterale, la sacrestia. Si ipotizza un impianto basilicale, a tre o a cinque navate, coperte da un tetto ligneo forse simile agli edifici sacri costruiti da Costantino a Roma e in Terra Santa. Ampiamente rimaneggiata dal figlio di Costantino, Costanzo II, fu in parte distrutta il 9 giugno 404 d.C. (forse solo il tetto e parte dell'interno) durante una rivolta dei partigiani di Giovanni Crisostomo, patriarca di Costantinopoli, deposto dall'imperatrice Eudossia, moglie di Arcadio (395-408 d.C.) e fu rinnovata il 10 ottobre 415 d.C. da Teodosio II (1221-1258). ${ }^{43} \mathrm{Nel} 532$ d.C. in seguito all'in-

${ }^{40}$ Cfr. Millet 1947.

${ }^{41}$ Cfr. Lamma 1950, 47-52.

${ }^{42}$ Per la storia della costruzione della chiesa cfr. Swift 1940; Fobelli 2005; Mainstone 2009; Enciclopedia cattolica IV, pp. 754-62.

${ }^{43}$ Mainstone 2009, 148-63, 296. Gli scavi condotti da Schneider (Scheneider 1941, 22-8) hanno portato alla luce alcuni frammenti della chiesa teodosiana appartenenti al portico. Sebbene le fonti non trasmettano informazioni più dettagliate della chiesa in quell'epoca, è stato ipotizzato che fosse preceduta da un quadriportico e avesse struttura basilicale a cinque navate sormontate 
cendio appiccato al Palazzo del Senato ${ }^{44}$ che la distrusse in parte insieme a una vasta porzione di città, Giustiniano decise di ricostruirla in modo più ardito e splendido, tentando di trovare il modo più appariscente per sottolineare il trionfo, eppur non definitivo, sugli avversari interni. Sommersa dalla più grande basilica che le succedette, del precedente edificio se ne è ritrovato solo qualche elemento della facciata grazie agli scavi condotti dall'Istituto Archeologico Tedesco. ${ }^{45}$ Il nuovo edificio doveva esaltare la vittoria dell'ortodossia, attestare la grandezza del governo e rappresentare l'animo delle genti, tanto che Procopio di Cesarea nel De aedificiis condanna la sedizione che l'aveva demolita come rivolta contro la fede, celebra la vittoria su di essa come affermazione dell'ortodossia e vede nello splendore del nuovo edificio il segno della Provvidenza Divina, la quale aveva voluto quella prova per glorificare la verità ed esaltare il sovrano che l'aveva difesa:

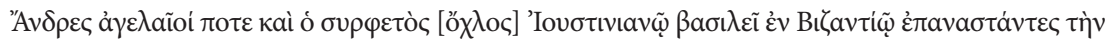

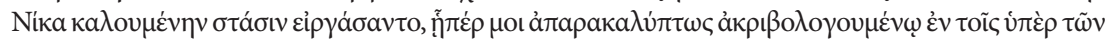

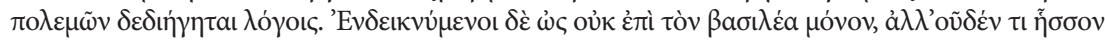

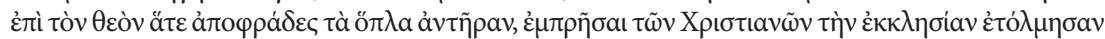

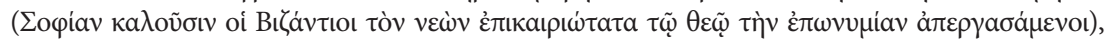

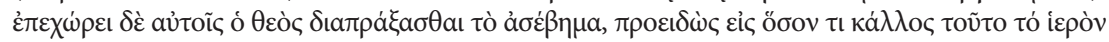
$\mu \varepsilon \tau \alpha \sigma \tau \eta \dot{\sigma \varepsilon} \sigma \theta \alpha \mathrm{l} \varepsilon \tilde{\mu} \mu \varepsilon \lambda \lambda \varepsilon v$. (Proc., Aed. 1.1.20-1) ${ }^{46}$

da gallerie con copertura lignea. Secondo Krautheimer (Krautheimer 1986, 70, 76, n. 27) la fronte dell'atrio misurava oltre 66 metri di larghezza e l'intero edificio doveva misurare 120 metri; l'impianto della chiesa teodosiana risaliva probabilmente al progetto di Costantino.

${ }^{44}$ Cfr. Proc., Bell. I 24,9: Procopio assegna un ruolo rilevante al "tempio della Sapienza" ponendolo all'inizio della catalogazione delle perdite del patrimonio architettonico costantinopolitano

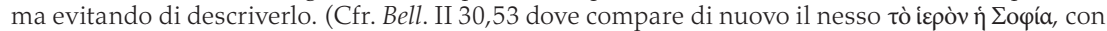
una connotazione cristiana; Bell. III 6,26 in cui il tempio è riferito a "Cristo, il grande Dio" nella sua accezione di Sapienza cui segue un inciso esplicativo della Sapienza come nomen sacrum). Usa il termine "tempio", arcaismo classicistico che appare un vezzo letterario a fronte delle questioni religiose (secondo Cesaretti 2011, 44-7).

${ }^{45}$ Cfr. Schneider 1936.

46 "Un tempo alcuni uomini dappoco e la feccia della città, essendosi sollevati a Bisanzio contro l'imperatore, provocarono la rivolta chiamata 'Nika' che ho descritto parlandone dettagliatamente e apertamente nei libri sulle guerre. Dimostrando che non solo essi presero le armi contro l'imperatore ma nondimeno contro Dio, empi quali erano, osarono incendiare la chiesa dei Cristiani (gli abitanti di Bisanzio chiamano 'Sofia' il tempio avendo forgiato l'epiteto più appropriato a Dio), e Dio concesse loro di compiere tale sacrilegio, prevedendo in quale magnifico edificio questo santuario stava per essere trasformato". La traduzione è dell'autrice di questo articolo.

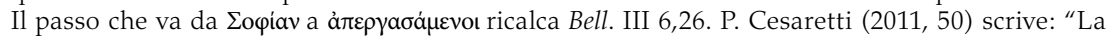
prima presentazione dell'edificio nel testo (...) si apre dunque con la medesima scena di violenza urbana contro la vecchia Santa Sofia che avevamo incontrato in Bell. I 24,19 (...) Prima della descrizione incontriamo dunque una celebrazione che si staglia su uno scenario che non è solo umano e urbano (la città) ma è anche divino, per la stretta correlazione tra azione divina e ope-

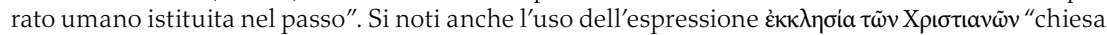
dei Cristiani" che connota il carattere cristiano dell'edificio, la cui bellezza è necessario farmaco dell'empietà che fu necessaria alla sua costruzione in un meccanismo di riscatto dalla colpa tipi- 
Identificando il regime con la fede vera, i nemici dell'una lo sono anche dell'altro e Dio protegge chi sulla Terra esalta la Sua sapienza. S. Sofia doveva assolvere a funzioni di rappresentanza sia episcopale sia imperiale. $\mathrm{Fu}$ Giustiniano a volere che la sua arte avesse una funzione rappresentata nella struttura e nella decorazione.

Lo studio approfondito delle prospettive del committente permette l'accesso alle circostanze storiche concomitanti alla nascita di un'opera d'arte. Esiste un nesso, spesso fin troppo trascurato, tra l'ambito storico del committente e il concetto artistico, intenzione o pretesa che l'opera architettonica tradisce. Destinatario di questa pretesa è l'osservatore in grado di recepire stimoli visivi. Il committente, in questo caso l'imperatore, può esercitare un notevole influsso sul contenuto e forma dell'opera, ma non è mai del tutto libero dalle sue scelte, perché deve sottomettersi alle tendenze e mode artistiche contemporanee. Se, invece, decide di evadere dalla routine artistica e ingaggia artisti provenienti da altri luoghi, la retorica sottesa all'opera sarà quella incomprensibile dell'unicità: un esempio in tal senso è colto nella chiesa di S. Sofia. ${ }^{47}$

Infatti, qualunque tentativo di far derivare, sia le singole forme sia l'insieme, da qualche altra opera è destinato a fallire..$^{48} \mathrm{~S}$. Sofia nella sua essenza non ha precedenti. Fu concepita come qualcosa di unico e tale unicum ineguagliabile doveva essere in primo luogo testimonianza delle mire universalistiche dell'imperatore in ambito politico, religioso, culturale. Giustiniano chiamò per realizzare la sua chiesa "unica" $i$ due architetti, progettisti e ingegneri Antemio di Tralle e Isidoro di Mileto, particolarmente versati nelle scienze matematiche e nella geometria, ottimi teorici, ma che sembra avessero comunque scarsa esperienza sul campo. Secondo Procopio a determinare la scelta fu Dio. ${ }^{49}$ Ai visitatori della chiesa di S. Sofia risultò chiaro che il gran numero di tipi di marmo scelto dai due progettisti per le pareti, le colonne, i capitelli, i pavimenti dovevano evocare lo statuto imperiale. Pare inverosimile che il porfido per S. Sofia sia stato importato dall'Egitto, come ritenevano W. R. Lethaby e H. Swainson..$^{50} \mathrm{Si}$ trattò di spolia trasportati a Bisanzio da luoghi lontani. Infatti l'imperatore "scrisse agli strateghi, ai satrapi, ai giudici, ai funzionari del fisco nelle province di cercare quanto trovassero di colonne, abachi, cancellate e ogni materiale per costruire il tempio. Tutti

camente cristiano. La sapienza è evidente non solo nel nome ma anche nei fatti dal momento che Dio acconsente all'empietà in vista della bellezza futura.

${ }^{47}$ Cfr. Brenk 2003, 14-15.

${ }^{48}$ Mainstone 1988, 159.

${ }^{49}$ Proc., Aed. 1.1.25.

${ }^{50}$ Lethaby \& Swainson 1894, 236. 
gli invitati da lui dai templi pagani, dagli antichi siti e dalle cave mandarono tutto all'imperatore Giustiniano da ogni provincia dell'Oriente e dell'Occidente, dal nord e dal sud e da tutte le isole". ${ }^{11}$ Sembra che colonne e ornamenti siano giunti dai templi di Diana a Efeso, di Atene, di Delfi, di Delo e di Osiride in Egitto. Le otto grandi colonne nella navata centrale, di verde antico (dalla Tessaglia) potrebbero essere state realizzate espressamente per la chiesa ${ }^{52} \mathrm{o}$ tratte dal tempio di Artemide ad Efeso ${ }^{53}$; altre colonne della chiesa provenivano, forse, da Roma in quanto Aureliano le aveva portate lì dal tempio di Heliopolis (Ba'albek). Per il rivestimento parietale fino alle volte furono usate, disposte specularmente, grandi lastre di marmo fatte giungere da Karystos (in marmo cipollino dell'Eubea), Docimo (Frigia), Chio (quello usato per la porta santa), dalla Numidia benché la vicina isola di Proconneso offrisse un marmo di grana fine, bianco talora venato di azzurro: tutta questa varietà di marmi è espressione della munificenza imperiale.

Oltre a ciò, la considerevole profusione di capitelli, per la maggior parte realizzati ex novo per S. Sofia, sono espressione della retorica imperiale. Delle 107 colonne che si trovano nella chiesa 40 sono al piano terra, 60 al piano del gineceo e 7 nella galleria più alta. Il pavimento era per un certo tratto in opus sectile e parte era rivestito da mosaici.

Era tradizione secolare che ogni imperatore romano facesse realizzare un'ornamentazione peculiare per gli edifici che costruiva; sulla base di questo va visto il carattere innovativo dei capitelli a traforo ${ }^{54}$; infatti la loro novità e forma evocano nello spettatore un senso di estraneità, elemento essenziale della retorica imperiale, mentre l'alterità esotica è il fine dell'estetica imperiale. I lavori, che iniziarono a 40 giorni dall'incendio, si protrassero per quasi sei anni e videro impegnati diecimila operai, guidati da cento capomastri. La basilica ha una pianta che fonde il rettangolo entro il quadrato $(75,60 \times 71,70 \mathrm{~m})$, con tre navate, arcate divisorie in doppio ordine, ed un'unica abside opposta all'ingresso, che all'esterno si presenta poligonale. La pianta ha probabilmente ricalcato quella della basilica costantiniana. ${ }^{55}$ L'ingresso è preceduto da un doppio nartece: l'esonartece, assai stretto e allungato, che serviva come passaggio tra l'atrio (oggi scomparso) e il nartece, l'ampio vestibolo che misura $60 \mathrm{~m}$ di lunghezza per $11 \mathrm{~m}$ di larghezza.

${ }^{51}$ Narratio de Sancta Sophia, Corpus scriptorum historiae byzantinae, Bonn 1843, p. 131. La traduzione è di P. Lamma $(1950,50)$.

${ }^{52}$ Lethaby \& Swainson 1894, 237.

${ }_{53}$ Enciclopedia Cattolica IV, p. 760.

${ }^{54}$ Cfr. Kautzsch 1936, 193-6, tav. 38, 644 a-b.

${ }_{55}$ Per un approfondimento sulla struttura basilicale: cfr. Foschi 2002, 12 ss. 
Su due blocchi del fregio della porta d'ingresso sono scolpiti sei agnelli di profilo, in moto verso una palma.

All'esonartece si accedeva da cinque porte, aggiunte dopo il crollo del 559 pur essendo come il nartece coperto da nove volte (Giustiniano fece costruire la decima volta), tra loro separate da archi, è profondo e alto la metà. Delle cinque porte in bronzo che danno accesso alla navata, la più celebre è quella centrale: la tripla Porta Reale, che era riservata all'ingresso della corte imperiale nella basilica, al di sopra della quale vi è un mosaico bizantino raffigurante la Maestà di Cristo in un mosaico a lunetta, ${ }^{56}$ mentre sulle altre, sempre su sfondo dorato sono raffigurate delle croci a contorno scuro, stelle a otto raggi, motivi geometrici di derivazione copta. Cristo ha nella mano sinistra un libro sul quale si legge la scritta in greco "Pace a voi. Io sono la luce del mondo ${ }^{\prime 57} \mathrm{e}$ a sinistra si prostra un imperatore. Ai lati di Cristo vi sono due dischi, a sinistra la Vergine e a destra un angelo: è stato detto che l'imperatore prega, la Vergine intercede e l'angelo sta di guardia alla chiesa. ${ }^{58}$

Un altro importante esempio della bellezza delle porte bronzee era rappresentato dalla porta dell'Orologio sulla quale in alto vi erano in monogrammi ageminati in argento i nomi degli imperatori Teofilo e Michele, e di Teodora. ${ }^{59}$ Dopo l'incendio, per ovviare a eventuali moti sismici, fu ideato sotto la platea di fondazione un vasto sistema di cisterne colme d'acqua con pilastri fondati direttamente sulla roccia e costruiti in blocchi di gres con graffe di metallo. Gli interni sono arricchiti con mosaici, marmi pregiati e stucchi. Nel corso degli anni sono stati aggiunti alcuni mausolei laterali.

All'interno, corridoi laterali riccamente decorati conducono al grande vano della navata centrale, dominato dalla mastodontica cupola, che poggia su un pennacchio ed archi, i quali scaricano il loro peso su quattro enormi pilastri. Nelle zone verso l'abside e verso l'ingresso due semi-cupole digradano da quella principale e poggiano su esedre a colonne. Nella fascia superiore della grande cupola una doppia fila di finestre, prima aperte ed in seguito parzialmente murate per aumentare la stabilità dell'edificio, che ne inondano di luce l'interno. Sulle navate laterali corrono i matronei, destinati alla corte imperiale, che assisteva alla celebrazione della messa da una

\footnotetext{
${ }^{56}$ Questi mosaici risalgono a Giustino II poiché né Procopio (De Aedificiis I), né Paolo Silenziario accennano a tale decorazione, contrariamente a un passo di Teofane, che parla di Giustino di cui ha dato prova A. Heisenberg $(1912,121-60)$ avanzando l'ipotesi che l'artista autore della decorazione sia Eulalio già accertato per i SS. Apostoli e che una poesia di Teodoro Prodromo, scoperta da A. Maiuri (1912, 360 ss.) cita fra i "principi della pittura".

${ }^{57}$ IO. 8.12 .

${ }^{58}$ Questa interpretazione va contro quanto pensa C. Osieczkowska 1934. Cfr. Stefanescu 1934 e Dolger 1935, secondo i quali l'imperatore prega e implora, la Vergine intercede e 1'Angelo, anonimo, sta di guardia a tutela della chiesa.

${ }^{59}$ E. H. Swift (1937) attribuisce quattro porte ad un'antica basilica costantiniana.
} 
posizione rialzata. Al di sopra dei matronei la muratura è perforata da due file sovrapposte di finestre di dimensioni variabili (più ampie al centro, più piccole verso i lati e nella fila inferiore).

L'effetto è quello di uno spazio incommensurabile e di leggerezza della copertura, che sembra come sospesa nell'aria. La decorazione interna fu integrata da Giustino II con cicli evangelici e con scene divenute poi canoniche del Dodecaorto, il sistema di dodici feste bizantine. La cupola riporta un Cristo Паvтокрát $\omega \rho$ benedicente, a mezzo busto. Per l'anatomia dei visi di Cristo e dei Santi sembra siano state utilizzate le descrizioni contenute in un libretto di Ulpius Romano: un esempio è S. Gregorio ritratto con la barba fumosa e l'occhio destro menomato da un incidente. L'abside è stato rinforzato all'esterno da alcuni contrafforti posticci. Uno di questi contiene una cappella con mosaici frammentari realizzati col sistema della doppia linea.

La chiesa venne consacrata il 27 dicembre 537 d.C. in presenza dell'imperatore, che in tale occasione avrebbe detto: "Gloria a Dio che mi ha fatto degno di questo! Ti ho superato, o Salomone!" ${ }^{\prime 60} \mathrm{e}$ dal popolo vennero esaltati soprattutto il pensiero direttivo, l'ispirazione, il consiglio di Giustiniano oltre che il suo contributo all'opera di realizzazione della chiesa, mentre ad Isidoro e Antemio fu attribuita la funzione, splendida e geniale, di tecnici. Per quattordici giorni si susseguirono pomposi festeggiamenti. Ma tanto entusiasmo non era destinato a durare a lungo.

Malgrado alcuni interventi di consolidamento, i pilastri di sostegno della cupola argentea non erano sufficientemente robusti per sostenere il peso della cupola di $31,38 \mathrm{~m}$ di diametro, elevata a $65 \mathrm{~m}$ di altezza, che era in conci di calcare (contrariamente alle pareti in mattoni) di grandi dimensioni collegati tra loro da grappe di ferro. ${ }^{61}$ Già lesionati durante la costruzione, i pilastri furono ulteriormente indeboliti dai terremoti del 553 d.C. e del 14 dicembre 557 d.C. La cupola, struttura architettonicamente troppo ardita, costruita con speciali mattoni cavi fabbricati a Rodi con un argilla particolarmente leggera, crollò in seguito a un terremoto il 7 maggio 558 d.C., insieme all'altare e all'ambone. ${ }^{22}$

Quello fu un anno di crisi, ci furono un'epidemia di peste, sconvolgimenti tellurici, carestie, minaccia degli Unni di Zabergan (559 d.C.) e, oltre a questi eventi, le conquiste occidentali avevano esaurito le forze dell'impero. Il crollo della cupola fu considerato un sinistro presagio: erano stati infranti

${ }^{60}$ Evagrio, Hist. Eccl. 1.4.31. Cfr. Narractio de Sancta Sophia, § 22 (= p. 105, 4-5 Preger); Romano il Melodo, Terremoti e incendi, str. 21.

${ }^{61}$ Si tratta della muratura a sacco in cui il parametro esterno è caratterizzato dalla disposizione dei conci in filari orizzontali intervallati da elementi ortogonali (diatoni e ortostati), atti a garantire l'ammorsamento del paramento al nucleo interno.

${ }^{62}$ Per un approfondimento sulla cupola si veda Millet 1923, Conant 1946. 
il simbolo della politica ortodossa, vanificate le speranze di una civiltà conservatrice di valori migliori. Bisognava di nuovo innalzare S. Sofia. ${ }^{63}$ Giustiniano si diede al restauro della chiesa che fu inaugurata di nuovo il 24 dicembre 563 d.C. alla presenza dell'imperatore e del patriarca Eutichio. La chiesa venne riaperta al culto nello stesso anno, dopo la costruzione di una nuova cupola più leggera e rialzata di circa 6 metri per distribuirne meglio il carico, aumentando le spinte verticali e diminuendo quelle orizzontali verso i muri di sostegno.

I lavori furono diretti da Isidoro il Giovane, nipote di uno degli architetti originari, che diminuì il diametro della cupola e ne aumentò l'altezza, addossandole all'esterno massicce muraglie di sostegno. La struttura fu inoltre consolidata con la costruzione di quattro alette-contrafforti ai lati, che racchiudono le scale interne. L'imperatore tutelò, inoltre, la sua Grande Chiesa dal punto di vista giuridico, all'interno delle Novellae stabilendo che per S. Sofia fosse limitato il numero di chierici e fosse impedita ogni alienazione di beni e gioco di interessi profani, evitando così che la chiesa divenisse oggetto di intrighi politici ${ }^{64}$ (535 d.C.); preservandola dalla possibilità che venisse venduta essa stessa o i suoi possessi, qualora fosse stato toccato l'interesse del fisco ${ }^{65}$ (537 d.C.); concedendo l'enfiteusi ai parenti degli economi della chiesa (544 d.C.). ${ }^{66}$

\section{LA DESCRIZIONE DI HAGHIA SOFIA NEL DE AEDIFICIIS DI PROCOPIO DI CESAREA}

Il De aedificiis dello storico bizantino Procopio di Cesarea (v-vI d.C.) ${ }^{67}$ opera scritta come un panegirico dell'imperatore Giustiniano, fu probabilmente parte di un tentativo di propaganda imperiale, un'opera forse commissionata in lode di un governo che aveva assolutamente bisogno del consenso. Infatti il regno di Giustiniano fu disastroso nonostante quanto appaia dal vanto militare, che l'imperatore non fece mai mancare

\footnotetext{
${ }^{63}$ Procopio di Gaza dirà: P.G. 87, 2840 "Era dunque la sciagura di ogni sciagura, il dolore di ogni dolore, il pianto di ogni pianto, il lamento di ogni lamento, più grande e più selvaggio". (La trad. è di P. Lamma 1950, 51).

${ }^{64}$ Nov. Just. III = p. 18-24 Schoell- Kroll.

${ }^{65}$ Nov. Just. XLVI = pp. 280-3 Schoell- Kroll.

${ }^{66}$ Nov. Just. CXX = pp. 578-91 Schoell- Kroll.

${ }^{67}$ Per Procopio di Cesarea, cfr. Downey 1963; Evans 1970, 220-1; Impellizzeri 1975, 218-30.
} 
nelle sue imprese ${ }^{68}$; le guerre furono dispendiose e le risorse finanziarie conservate da Anastasio furono presto esaurite; la peste ridusse la popolazione dell'impero a circa il sessanta per cento del suo precedente totale, ${ }^{69}$ e l'erario pubblico versò in disastrose condizioni dal punto di vista delle entrate; l'impero fu dilaniato dalla presenza di eresie. Esso contiene un resoconto sul programma delle costruzioni promosse dall'imperatore Giustiniano, ${ }^{70}$ reso dettagliato dall'uso da parte dell'autore di fonti ufficiali, grazie al quale è stato possibile essere ben informati sugli edifici giustinianei della capitale e di altre regioni. La città descritta da Procopio è quella successiva ai tumulti civili, quali quello "Nika", ${ }^{71}$ che, anche grazie a questi, si riafferma cantiere principale del mondo mediterraneo, sollecitando tecniche, saperi progettuali e capacità organizzative, e convogliandoli in uno sforzo di trasformazione che imprimerà alla forma urbana i suoi tratti permanenti. Da questo punto di vista la narrazione encomiastica di Procopio trova sostanziale corrispondenza nell'insieme delle attività costruttive promosse da Giustiniano. Giustiniano, infatti, è qui rappresentato come un sovrano-costruttore ${ }^{72}$ che si muove in quattro direzioni diverse: rinnovo e rafforzamento dei segni architettonici dell'autorità imperiale; riqualificazione del volto della città in quello di centro dominante dell'ecumene cristiano; adeguamento di alcune infrastrutture civili; interventi di prestigio e adeguata sistemazione dell'ampia fascia suburbana europea e asiatica.

L'autore enumera anche gli atti di provvidenza imperiale nelle province e in ogni luogo dell'impero oltre la capitale e dimostra come la committenza imperiale assuma ufficialmente un nuovo stile, ${ }^{73}$ quello del manifestare solennemente, attraverso lo strumento architettonico, la pietas cristiana del Dominus sovrano, che si mostra nuovo Salomone. ${ }^{74}$ La Costantinopoli presentata nel I libro sembra configurarsi secondo un modello che persegue l'intento dell'imperatore di portarla a compimento come Nea Roma e Nea Ierosolima; l'imperatore ne mostra in modi diversi le contraddizioni,

\footnotetext{
${ }^{68}$ Infatti nei proemi delle sue leggi frequenti erano i topoi inerenti ai successi ottenuti nelle guerre combattute sotto il suo regno, felicemente conclusesi in vittorie sui nemici dell'Impero. Cfr. Cod. Just. 1.27.1.(= pp. 389-99 Kruger) e Nov. XXX, 11. 2 (= p. 234 Schoell- Kroll).

${ }^{69}$ Cfr. Russell 1958, 37-42.

${ }^{70}$ Cfr. Evans 1970, 218-23.

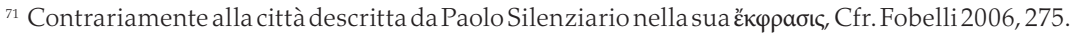

${ }^{72}$ Cfr. Proc., Aed. 1.1.12. Al contrario, negli Anecdota, Procopio imputa ai meccanismi fiscali e alle politiche sociali ed economiche imperiali gli aspetti negativi del quadro che ha dinanzi agli occhi: Anec. 26 "nessuno riuscì [più] ad avere cura degli edifici pubblici e nelle città non vi fu più illuminazione pubblica, né altro conforto per gli abitanti. Rimasero, così, abbandonati per lo più anche i teatri, gli ippodromi, i circhi". (trad. a cura di A. Marletta, in Concina 2002, 44).

${ }^{73}$ Cfr. Mango 2004.

${ }^{74}$ Evagr., Hist. Eccl. 1.4.31.
} 
che rispecchiano gli estremi contrapposti entro i quali la città del vi secolo vive le sue sorti. Giustiniano è il nuovo fondatore della città, che egli trasforma da metropoli a megalopoli cristiana. A Costantino e a Giustiniano si guarda quali co-fondatori, ${ }^{75}$ tanto che un anonimo del xv secolo scrive:

fu dunque il Grande Costantino che rese bella

la città celebratissima che vedi (...)

non meno grandemente l'adornò Giustiniano

fece S. Sofia, meraviglioso spettacolo

e in valore raggiunse la santissima Sion. ${ }^{76}$

In particolare nel $1^{\circ}$ capitolo del primo libro l'autore offre una trattazione dettagliata dei problemi legati alla costruzione e all'andamento dei lavori della chiesa di S. Sofia costruita negli anni $532-537$ e inaugurata il 27

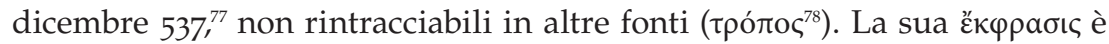
paragonabile a quella di Coricio di Gaza, che descrive le chiese della sua città $^{79}$ per la tecnica di descrizione, in quanto Procopio enfatizza l'effetto della bellezza della chiesa sul visitatore, i suoi colori, la varietà dei materiali, ed esprime tutto questo in un linguaggio ricco di similitudini e metafore ${ }^{80}$ Egli si concentra sull'architettura, sulla luce che pervade l'interno e sui colori dei marmi. Probabilmente la chiesa giustinianea era aniconica nella decorazione, ${ }^{81}$ sebbene potrebbe essere imprudente dedurre questa informazione solo dall'opera di Procopio, per il fatto che egli non menziona mai decorazioni pittoriche nella basilica giustinianea. E, mentre l'intero capitolo dedicato a S. Sofia si basa sull'ispirazione e intervento divini, manca un'esplicita connessione tra le parti della chiesa e i significati teologici che, invece, si trovano in altri testi del vi secolo. ${ }^{82}$ Tuttavia la trattazione dello storico, di cui alcuni studiosi hanno sottolineato l'atteggiamento e il lin-

\footnotetext{
${ }^{75}$ Si veda, ad esempio, anche il mosaico della lunetta del vestibolo sud della chiesa di S. Sofia, dove sono rappresentati Costantino e Giustiniano che offrono alla Vergine i modelli di Costantinopoli e della Basilica di S. Sofia.

${ }^{76}$ Traduzione italiana di E. Concina $(2002,43)$.

${ }_{77}$ Il poeta Paolo Silenziario, invece, tratta della seconda Santa Sofia giustinianea, ricostruita negli anni 558-562 dopo il crollo di una parte della cupola e dell'arcata orientale e inaugurata il 24 dicembre 562. Per il testo greco, la traduzione e il commento si veda Fobelli 2005.

${ }^{78}$ Procopio offre una descrizione del $\tau \rho$ ótoc, ovvero del "modo in cui" qualcosa è stato realizzato dove le imprese dei personaggi legati al monumento acquistano un rilievo particolare (cfr. Aed. 2.3.1).

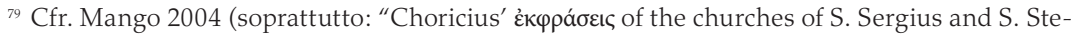
phen at Gaza", p. 60 ss).

${ }^{80} \mathrm{Vd}$. soprattutto Aed. 1.1.34-5 e 1.1.59.

${ }^{81}$ Cfr. Mundell 1998, 70. C. Mango (2004, soprattutto 62, 64 ss.) sottolinea il contrasto con la decorazione pittorica della chiesa di S. Sergio a Gaza descritta da Coricio.

${ }^{82}$ Corippo, Iust., 4.288: un passo che, secondo A. Cameron $(1985,100)$ è stato ritenuto a torto una descrizione letteraria della chiesa, rimandando così a C. Mango (2004, 55 ss.) sulla descrizione della cattedrale di Edessa, ricostruita a metà del VI secolo.
} 


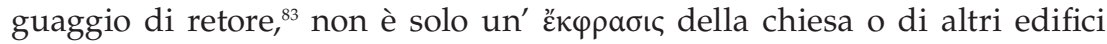
monumentali, ma un tributo encomiastico all'imperatore.

Nel proemio della sua opera (1.1.6-11), l'autore mette in evidenza il ruolo avuto dall'imperatore. A Giustiniano lo storico attribuisce il merito di aver esteso il territorio dello stato con le guerre di conquista

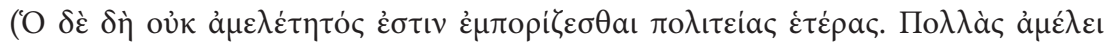

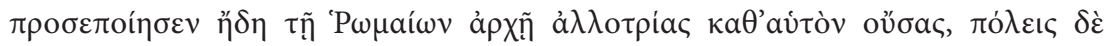

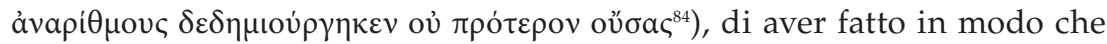

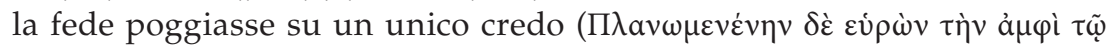

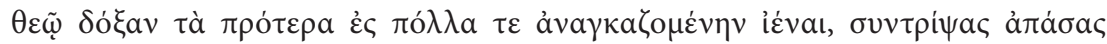

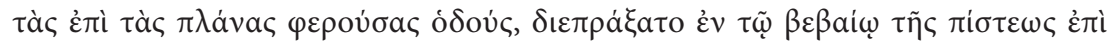

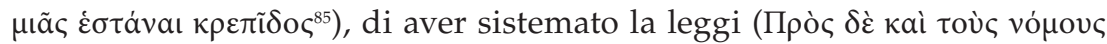

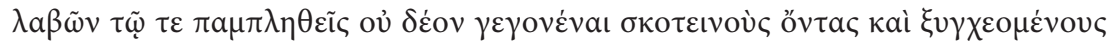

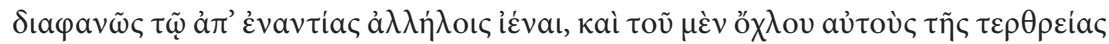

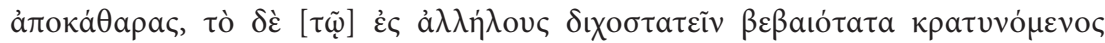
$\delta\left\llcorner\varepsilon \sigma \omega \sigma \sigma \alpha 0^{86}\right)$, di aver ignorato le accuse di coloro che gli tendevano insi-

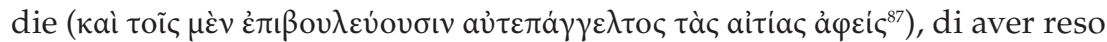

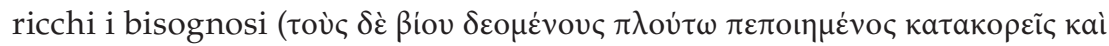

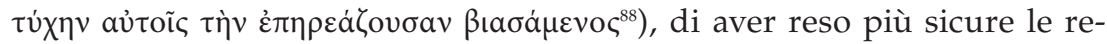

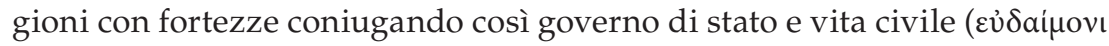

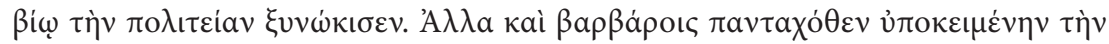

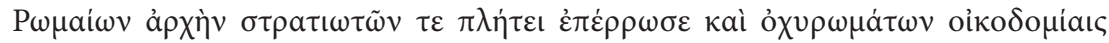

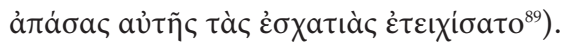

${ }^{83}$ Fra i molti studiosi che hanno riconosciuto il valore retorico dell'opera: James 2007, Webb 2000, Whytby 2000a, 2000b.

${ }_{84}$ "Invero quello (Giustiniano) ha avuto l'abilità di conquistare altri stati. Per esempio ha aggiunto ad esso molti altri non appartenenti all'impero romano, ha fondato innumerevoli città non esistenti prima". La traduzione è dell'autrice di questo articolo. Giustiniano riacquisiva territori appartenenti alla pars Occidentis dell'Impero, mentre assolute novità sono le iniziative diplomatiche di Giustiniano verso popolazioni barbariche che egli legava all'Impero con vincoli religiosi ed economici e ciò giustifica l'acquisizione e l'uso del verbo tecnico $\delta \eta \mu \iota v \rho \gamma \varepsilon ́ \omega$ per indicare la creazione ex nihilo, presente nel solo De aedificiis con 22 esempi.

${ }_{85}$ "Avendo trovato che la fede in Dio era invischiata in errori ed era costretta a vagare in varie direzioni, dopo aver distrutto tutte le vie che portavano all'errore, ottenne che la fede poggiasse sul saldo fondamento di un unico credo". La traduzione è dell'autrice di questo articolo.

86 "Avendo trovato che le leggi, moltiplicatesi non convenientemente, erano divenute oscure ed essendo cadute in reciproca contraddizione, chiaramente erano confuse, dopo averle purificate dalla massa di vane ciarle e rafforzate solidamente dall'essere discordanti fra loro, le salvò". La traduzione è dell'autrice di questo articolo.

87 "inoltre, rinunciando volontariamente alle accuse contro coloro che gli tendevano insidie". La traduzione è dell'autrice di questo articolo.

88 "rendendo sazi di ricchezza i bisognosi, e forzando il loro destino di oppressione". La traduzione è dell'autrice di questo articolo.

89 "coniugò governo di stato e vita felice. Rafforzò anche con molte truppe l'impero romano, soggetto ai barbari da ogni parte, e fortificò tutte le regioni estreme con la costruzione di for- 
Operando, quindi, un confronto con Ciro, considerato il fondatore

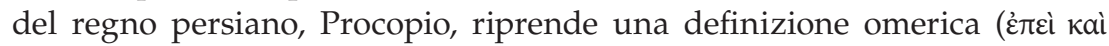

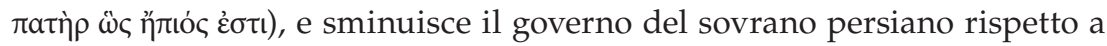
quello di Giustiniano (§§ 12-15). ${ }^{90}$

L'imperatore, oltre a essere definito promotore e autore di una salda sistemazione delle leggi e della religione, compositore degli scontri nella vita civile, è anche benefattore e magnanimo ( $\varepsilon \dot{\varepsilon} \rho \gamma \varepsilon \dot{\tau} \eta \varsigma)$ in quanto ha risparmiato coloro che lo avevano tradito e insidiato e ha permesso loro di mantenere il proprio rango sociale..$^{91}$

L'autore dichiara quindi lo scopo della stesura dell'opera: descrivere le opere realizzate da Giustiniano, sì che i posteri non cadano nell'errore di attribuirle a precedenti imperatori; già in questa affermazione c'è tutta l'eccezionalità del fatto che è stato un solo uomo, in seguito indicato come

tezze". La traduzione è dell'autrice di questo articolo. Un particolare rilievo è concesso al ter-

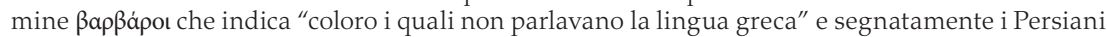
(anche se non venne conseguita una vittoria conclusiva), i Vandali e gli Ostrogoti contro i quali i generali dell'imperatore hanno conseguito vittorie celebrate in un'altra opera di Procopio (cfr. Bell. I 1,1 per la contrapposizione tra "barbari di Oriente e d'Occidente". Retoricamente sembra quasi che l'autore si serva di un'iperbole e di accentuata enfasi quando parla di ciò che avrebbe

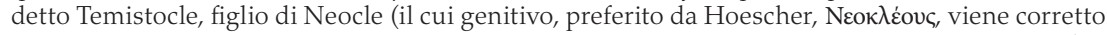

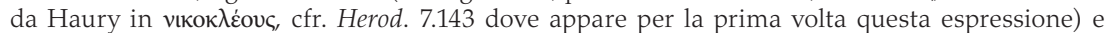
quando sottolinea l'opera giustinianea di un vero e proprio "restauro" dell'impero, da un punto di vista legislativo, religioso, urbano e sociale, in uno stile chiaro anche se caratterizzato da periodi talvolta lunghi tipici dello stile retorico tardoantico. Procopio attinge alle Vite Parallele di Plutarco questa massima di Temistocle (Temistocle 2.3; Cimone 9.1), sottolineando la contrapposizione tra le parole autocelebrative del primo e i fatti del secondo. Negli Anecdota $(6,21 ; 8,4 ;$ al.) Giustiniano è, invece, presentato non come rimedio ma come agente del "perturbamento", ed è il governo di Anastasio I (491-518) a caratterizzarsi per la buona amministrazione della città (cfr. Bell. I 10,11). La trasformazione operata da Giustiniano si può assimilare a una cura di tipo medico, in base a una caratterizzazione terapeutica del governo imperiale ben nota alla tradizione classica e alla propaganda giustinianea (cfr. Giust., Nov. 111).

${ }^{90}$ Ciò che caratterizza il discorso di Procopio è il fatto che esso sia intriso di riferimenti ad autori che egli ha apprezzato durante i suoi anni di formazione giovanile, e ciò è particolarmente rintracciabile in questo passo dove l'autore fa una citazione omerica, tratta da Od. II 47 e XV 152. Paragonando il governo imperiale a quello di Ciro, che è forse stato ingigantito da Senofonte, dimostra di conoscere le opere dello storiografo (e soprattutto la Ciropedia) riconoscendo potere alla parola e merito all'abilità storica. Procopio usa una metafora in cui paragona il governo del Persiano ad un gioco per bambini, se confrontato con quello giustinianeo, e qui si intravede una certa debolezza dell'impero barbarico contro cui Giustiniano non concluse mai una vittoria definitiva. L'imperatore, infatti, mantenne solo lo status quo precedente alla campagna del 545-557 d.C. con una pace di cinquanta anni (561 d.C.) che confermò i confini contesi dell'Armenia e della Mesopotamia. Tuttavia l'intero passo fa posto all'ironia dell'autore, che afferma la superiorità del governo imperiale contrariamente a quanto realmente si è verificato negli eventi bellici, enfatizzando un aspetto non veritiero. Un accostamento meno di parte si legge in Bell. II 2,14-15, dove è costante la deminutio Cyrii a fronte della "nuova" sovranità romano- cristiana (cfr. Eus., Vita di Costantino I 7; Proc., Panegirico per l'imperatore Anastasio $\S 25=$ p.55, 427-40 Matino).

${ }^{91}$ Il ritratto dell'imperatore Giustiano tracciato da Procopio è molto simile a quello delineato da Agapeto nello speculum principis: immagine (å $\gamma \alpha \lambda \mu \alpha)$ della pietà, immobile e impassibile, l'impe-

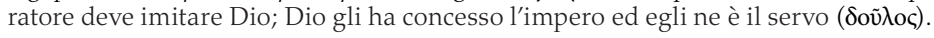


ispirato da Dio, ad aver realizzato queste opere e in particolare la chiesa di S. Sofia distrutta dai rivoltosi ${ }^{92}$ (gennaio 562 d.C.):

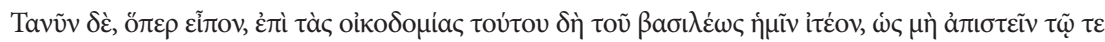

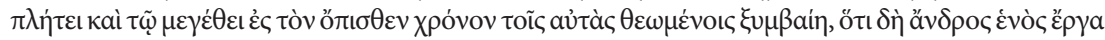

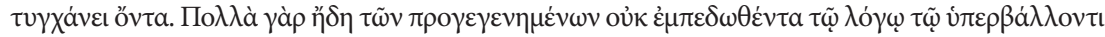

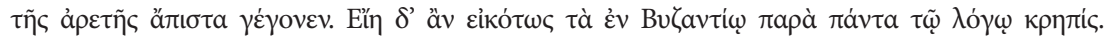

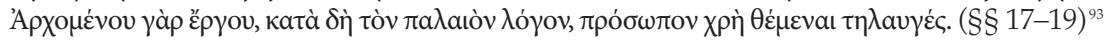

La rivolta, presentata come un'empietà (ảoś $\beta \eta \mu \alpha)$, è stata voluta da uomini che hanno preso le armi contro Dio e contro l'imperatore eletto da Dio; essa era, però, considerata dallo storico una provvidenziale occasione per l'imperatore di ricostruirla in modo più splendido e fastoso. Da questo momento in poi (soprattutto dal § 22) Procopio si sforzerà di mostrare come l'agire di Dio e del sovrano si intreccino indissolubilmente.

Dio ha permesso la distruzione della chiesa durante la rivolta "Nika", ma l'autore immagina che i Cristiani avrebbero sicuramente rivolto a sé stessi l'augurio di tale distruzione se avessero saputo come sarebbe divenuta la chiesa $\left(\S 22^{94}\right)$. Ancora prima di enumerare i dettagli aggiunti

${ }^{92}$ La rivolta "Nika" è trattata più dettagliatamente da Procopio in Pers. 1.24.10 (ma si veda anche Anec. 12,12) e da Giovanni Malala, Chronographia, 17.71. Il contemporaneo di Procopio Romano il Melodo († c.a. 555) dedicò gran parte del suo componimento Terremoti e incendi (n. $54=$ pp. 452-71 Maisano), datato al 532, alla distruzione di S. Sofia e al progetto di ricostruzione di Giustiniano.

93 "Ora dunque bisogna rivolgerci, come ho detto, alle costruzioni di questo imperatore, per impedire che capiti ai posteri di attribuirle per quantità e magnificenza all'epoca precedente, poiché sono certamente opera di un solo uomo. Infatti molte delle realizzazioni del passato, non confermate dal testo scritto, sono incredibili per chi le visita a causa della loro qualità. Naturalmente gli edifici di Bisanzio saranno innanzitutto il fondamento del mio discorso. Infatti, "a un'opera che si comincia", secondo un antico detto, "è opportuno dare una splendida facciata"". La traduzione è dell'autrice di questo articolo. In una klimax ascendente, l'autore sottolinea gli atti di benevolenza imperiale nei confronti di quanti hanno attentato alla sua vita, e soprattutto consoli

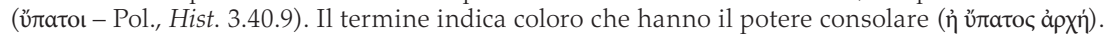
Un topos presente nel passo, è l'importanza del testo scritto che eterna, anche per i posteri, la bellezza degli edifici della città, la cui costruzione deve essere attribuita al solo imperatore. Compare inoltre la citazione tratta da Pindaro (Olym. 6,4); da sottolineare l'uso del toponimo Bisanzio, preferito da Procopio, nonostante questo termine indichi l'originaria città di epoca greco-romana.

${ }^{94}$ In questo paragrafo sembra presentarsi il topos dell'eventualità, che si conclude con la conseguenza inevitabile dell'ulteriore dimostrazione della magnificenza della chiesa, luogo sacro, "tempio" come sarà detto in seguito (Proc., Aed. I 1.30) riconosciuta dai Cristiani che in essa pregano.

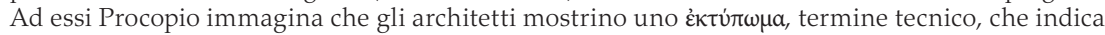
"impronta, effige, ritratto, bassorilievo" (cfr. Plat., Tim. 50) anche se qui deve essere inteso con il senso più tecnico di "modello". L'aspetto esteriore della chiesa è invece reso con il termine tecnico

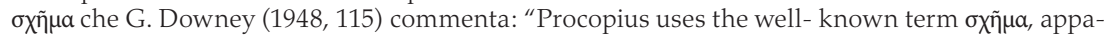
rently to mean ground plan", mentre Liddell-Scott-Jones (Lexicon, p. 1745) lo definiscono "form, shape, figure". Generalmente indica la pianta di un edificio ed è di uso tecnico. La ricostruzione della chiesa è presentata come una deliberazione individuale, così come la scelta dei collaboratori (cfr. §§ 25-26 in cui il sovrano sceglie con suo libero discernimento i più adatti all'impresa, ma Dio predispone per lui le competenze atte a soddisfare il suo intento. Cfr. Romano il Melodo, Can- 
per volere dell'imperatore, di dare cioè testimonianza scritta ai posteri sulla chiesa, che in precedenza aveva già detto essere mancante, ${ }^{95}$ Procopio ribadisce l'aspetto imponente e la bellezza della chiesa, certo che i lettori e i visitatori avrebbero compreso il suo entusiasmo. Per realizzare quest'unicum del panorama architettonico civile, Giustiniano chiamò architetti da tutto il mondo, fra cui i più importanti Isidoro di Mileto e Antemio di Tralle, scelti grazie alla benevolenza di Dio che concesse all'imperatore di saper porsi accanto uomini degni di servirlo:

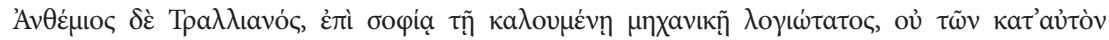

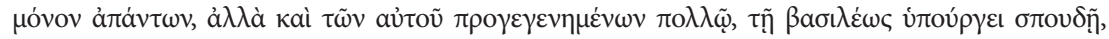

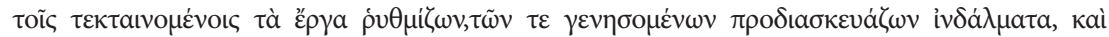

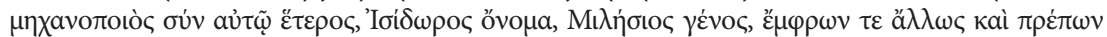

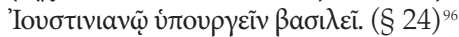

tici (a cura di R. Maisano, Torino 2002, II, 467, 471): i rivoltosi si erano ribellati contro Dio distruggendo le sue basiliche, ma in poco tempo la coppia imperiale Giustiniano e Teodora risollevarono tutta la chiesa e ora la chiesa era ricostruita con tanti ornamenti da imitare il cielo e il trono divino.

${ }_{95}$ Aed. I 1. 18.

96 "Antemio di Tralle, di gran lunga il più abile nella disciplina chiamata ingegneria, non solo fra tutti i contemporanei, ma anche fra i suoi predecessori, si mise al servizio dello zelo dell'imperatore, distribuendo i compiti ai costruttori, preparando innanzitutto i disegni della futura $\mathrm{CO}^{-}$ struzione; c'era insieme con lui un altro ingegnere, Isidoro di nome, Milesio di origine, uomo intelligente e degno di servire l'imperatore Giustiniano". La traduzione è dell'autrice di questo articolo. Cfr. Agazia, Storie 5.6.3-5; 5.7.1-5; 5.8.1-4 per la biografia di Antemio di Tralle (vd. anche "Anthemios di Tralle" in EAA I, pp. 412-13; "Anthemios of Tralles" in ODB I p. 109 s.v.; in PLRE IIIa pp.88-9). In questo paragrafo sono numerosi i termini tecnici: $\tau \varepsilon \chi v i \tau a$ ha il significato generico di "esperti, periti, artefici" qui reso con "architetti". Liddell-Scott-Jones commentano "artificer, craftman, opp. to $\gamma \varepsilon \omega \rho \gamma o ́$ " " (cfr. OC X, 6.6; Arist., Pol. 126 b26) aggiungendo "a man who does or handles a thing by the rules of art, skilled workman" (LSJ, Lexic. vol. II, p. 1785; cfr. Narractio de Sancta Sophia §7, p. 82,13 Preger). Cfr. Paolo Silenziario definisce Antemio con il ter-

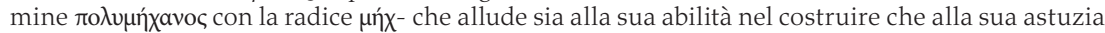
(Fobelli 2005) usato con il significato di "dai molti espedienti, ricco di artifici" anche in Omero per designare Odisseo (Cfr. Agazia, Storie 5.7.1-5; 5.8.3-5); la disciplina nella quale appare versato

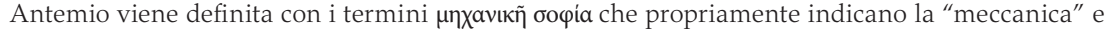
1' "ingegneria", (cfr. Arist., Metaph. 107 a), "the science of mechanics" (LSJ, Lexic. voI. II, p. 1131) comprendente una serie di conoscenze teoriche distinte dalla pratica costruttiva del cantiere esercitata dall'architetto, il $\mu \eta \chi a v ı$ ó

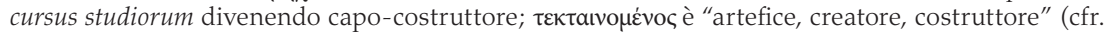
Plat., Tim. 28c); il termine $\mu \eta \chi a v o \pi o$ có implica l'aspetto eminentemente pratico e applicativo della "scienza delle costruzioni", incluse anche le funzioni del "progettista"; " iv $\delta \alpha \mu \mu$ ha il significato di "forma, apparenza" ma qui è reso con il significato più tecnico e concreto di "progetto, disegno" e Downey $(1948,115)$ spiega: "i $v \delta a ́ \lambda \mu \alpha \tau \alpha$ e $\sigma \kappa ı \alpha \gamma \rho \alpha \varphi$ á, in non- architectural usage, both may carry the connotation of two- dimensional or three- dimensional view, (...) there is nothing to prove that anything more complicated than a diagram or ground plant is meant", disegni progettuali che potevano consistere in vedute bidimensionali e tridimensionali; è la "benevolenza" di Dio a concedere a Giustiniano di sapersi porre accanto uomini adatti a servirne lo zelo, $\tau \mu$ í, che è anche "onore, stima, offerta, ricompensa", tuttavia è anche grazie al voũc ("senno, saggezza, mente" quest'ultima in quanto sede di avvedutezza) che è possibile la realizzazione della chiesa. Il termine è commentato da Liddell-Scott-Jones "worship, esteem, honour, dignity lordship, but refered to God compliments, offering" (Lexic. vol. II, p.1793-4, il corsivo è dell'autrice di questo articolo). Il paragrafo presenta periodi molto lunghi in conformità all'uso tardo antico del discorso retorico. 


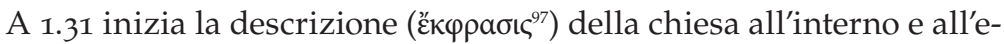
sterno che si protrarrà fino al paragrafo 66. La descrizione, inserita in un contesto di tipo celebrativo trova giustificazione nella sua pura e semplice esistenza proponendo immagini che contribuiscono a sottolineare i valori di cui il testo si fa portatore. Nel suo panegirico, Procopio, proponendo la descrizione, apparentemente solo architettonica e strutturale della chiesa di S. Sofia, prospetta all'ascoltatore dettagli che sottolineano il carattere cristiano dell'opera, ${ }^{98}$ non facendo esplicitamente riferimento a significati allegorici intrinseci agli stessi. ${ }^{99}$ Inoltre Procopio si inserisce perfettamente nella temperie culturale tardoantica poiché parla della chiesa che è dinanzi ai suoi occhi come di un $\theta \dot{\varepsilon} \alpha \mu \alpha$, di uno "spettacolo" che si erge sulla città e dinanzi alla cui bellezza gli spettatori si trovano in difficoltà, non sapendo

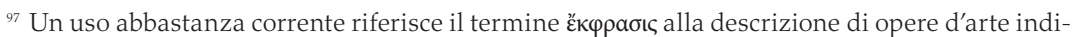
viduando in esse un momento paradigmatico del rapporto fra arte figurativa ed arte della parola, i loro linguaggi e l'affermazione della supremazia dell'una sull'altra. Tuttavia questo non esaurisce il significato che gli antichi davano al termine, anche se le indicazioni da loro fornite non

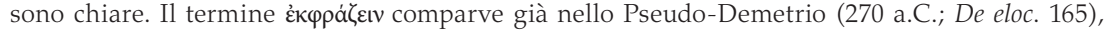
poi venne usato nella trattatistica ellenistica e penetrò nel mondo romano, ma fino a tale epoca si parlò di દ̉vápүદıa (capacità di far risaltare con vividezza ciò che si dice, in modo che chi ascolta possa vederlo con i propri occhi. Cfr. Quint., Ist. 6.2.29-32: l'autore evoca immagini nella mente dell'ascoltatore e così un passo ecfrastico, intensificazione di una scena, è importante nella narrazione e partecipa all'effetto persuasivo del testo), anche se questo termine non coincide con quello di Ěk $\varphi \rho a \sigma ı c$, sarà di essa la qualità più apprezzata. La non chiara elaborazione concettuale è sottolineata dall'uso in Quintiliano di termini quali descriptio (Quint., Rhet. 8.3.63-9; cfr. Rhetorica ad Herennium 4.39.51), demonstratio, evidentia, illustratio, rapraesentatio. Questo concetto si fissa piuttosto lentamente e trova una sua definizione con la Seconda Sofistica (fine I secolo- II secolo d.C.) nella trattatistica retorica che la colloca fra i Progymnasmata di Teone (I sec. d.C. cfr. Progymnasmata. Introduzione (a cura di M. Papillon, Paris 1997), Ermogene (II sec. d.C.), Aftonio (IV sec. d.C., autore della famosa Descrizione dell'Acropoli di Alessandria sotto forma di una visita guidata),

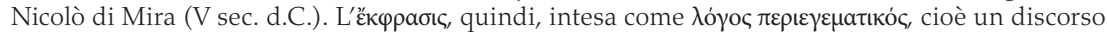
descrittivo che rende visibile ciò di cui si parla, ha per oggetto una gran varietà di temi, persone,

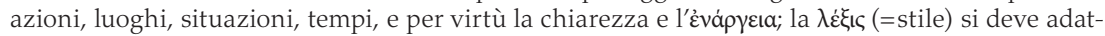
tare al tema. La descrizione, risultato della combinazione di queste componenti, è un oggetto a sé stante, un esercizio che si traduce in un discorso imperniato su una descrizione oggettiva del tema scelto. Ma non è detto che essa debba avere le caratteristiche del progymnasma, anche se si possono vedere gli esempi portati dai trattatisti nei quali queste si fondono con la narrazione (cfr. il combattimento notturno dei Plateesi assediati in Tuc., Hist. 3.20-3, portato come esempio da Ermogene, cfr. Gualandri 1994, 301) o che segnano una lunga pausa (Hom., Il. 18.478-608 in cui è presente la descrizione delle armi di Achille, esempio portato da Teone, cfr. Gualandri 1994, 301) o tocchi descrittivi (Hom., Il. 217-19 con la descrizione di Tersite; esempio presente in Ermogene e Teone). In età tardoantica il concetto può essere considerato l'elemento che guida l'attenzione su ciò di cui l'autore parla e l'elemento descrittivo pervade tutta la produzione letteraria non solo quella finalizzata alla celebrazione

${ }_{98}$ Cfr. Cameron 1985, 90: "One feature of the Buildings, however is its Christian framework. This is a work written with a certain purpose- to appeal to the imperial court- and it would be extraordinary if it did not make use of imperial Christian ideology". (Il corsivo è dell'autrice di questo articolo).

${ }_{99}$ L'interpretazione di significati metaforici interni all'opera sono stati interpretati e letti dai soli studiosi di architettura o storia dell'arte come E. Concina (2002, 62 ss).
} 
come porsi. Infatti, mentre in età classica il componimento è caratterizzato da una immagine di organicità strutturale, in epoca tarda sono noti fenomeni come l'attenuarsi del disegno compositivo generale che porta in primo piano i particolari, la costruzione di elementi giustapposti più che amalgamati in continuum, l'infrangersi dell'insieme in unità, la tendenza episodica, cui si unisce la presenza di descrizioni, come aspetto di ripudio di schemi classici, un diverso modo di narrare. Le descrizioni sono testimonianze preziose, infatti esse- sia pur attraverso il filtro delle convenzioni letterarie- recepiscono le trasformazioni del mondo esterno, la cui immagine si fa più ricca di colori. L'insistenza sull'interpretazione del mondo esterno nella descrizione rivela un profondo desiderio di vedere e osservare. Spesso l'autore si pone dinanzi all'opera che descrive come di fronte ad uno spettacolo. Il paradigma del $\theta \dot{\varepsilon} \alpha \mu a$ consente a Procopio di apprezzare il monstrum artistico e architettonico che è la chiesa di Santa Sofia, ${ }^{100}$ e di prefigurare uno nuovo statuto della chiesa quale "meraviglia" del mondo in termini immanenti a quelli del miracolo: $\theta \dot{\alpha} \alpha$ a la meraviglia, $\theta$ aṽ $\mu \alpha$ il miracolo. ${ }^{101}$ L'autore presenta, quindi, una meraviglia del mondo umano ma che è anche

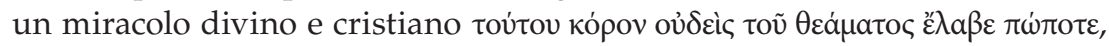
"di questo spettacolo nessuno ha mai avuto sazietà" (§ 63).

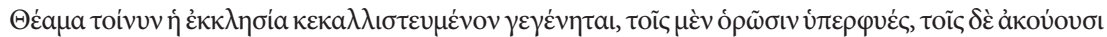

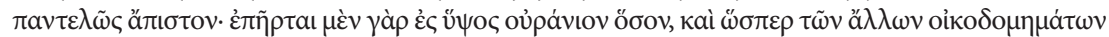

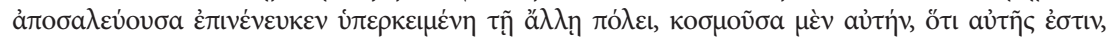

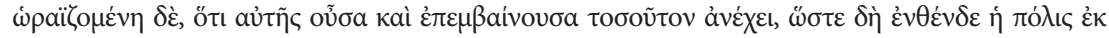

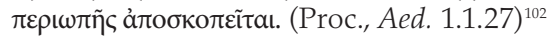

${ }^{100}$ Cfr. Aed.. II 1,3 in cui Procopio esprime un giudizio negativo sulle Piramidi, che conosceva e che rientravano nel canone delle sette meraviglie del mondo definite $\theta \dot{\varepsilon} \alpha \mu \alpha \tau \alpha-$ vd. in RE Supplbd. X, lemma "Weltwunder", coll. 1020-30 (Eanowski).

${ }^{101}$ Cfr. Dagron 1984, 41-2. Nella posteriore Narratio de Sancta Sofia, indagata da Dagron meraviglia e miracolo coopereranno nell'intero processo che procede dalla rivelazione angelica al senso ultimo della costruzione.

102 "La chiesa costituisce uno spettacolo di grandissima bellezza, straordinaria per chi la contempla, assolutamente incredibile per chi ne sente parlare. Infatti essa si erge fin quasi al cielo, e quasi ondeggiando svetta sugli altri edifici sovrastando tutta la città, adornandola, poiché appartiene a questa ma essendone abbellita, poiché, appartenendo a questa e svettando, si eleva tanto che dalla sua cima la città può essere guardata dall'alto". La traduzione è dell'autrice di questo

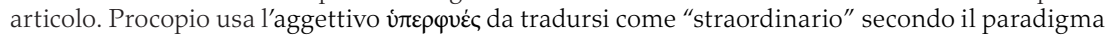

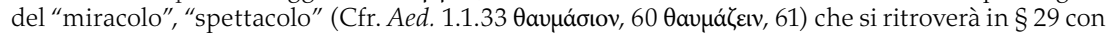
l'accezione prevalente di "straordinario, eccezionale" e che nelle Guerre (Bell. VIII 31,19) viene usato per definire il cavallo del re goto Totila che dà dimostrazione della propria bravura equestre nello spazio tra i due eserciti; con il termine tecnico $\theta \dot{\varepsilon} \alpha \mu \alpha$ venivano indicate anche le "sette meraviglie" del mondo ovvero i sette "spettacoli", cfr. STRAB., Geo. XIV 2,5 (652 C); Plut., Mor. 983e (L'intelligenza degli animali); Anonymus de incredibilibus 2; pertanto, come afferma P. Cesaretti $(2011,57)$, "La Santa Sofia giustinianea appare così l'opera di un Dio taumaturgo e signore dei mi-

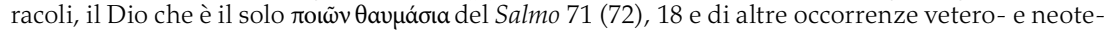
stamentarie. Miracolo essa stessa, realizzata attraverso un intervento che non è umano (...)". Cfr. 


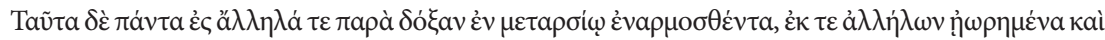

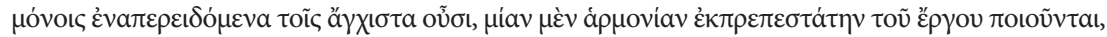

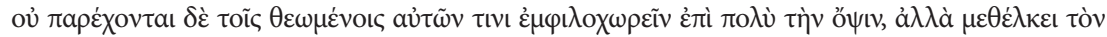

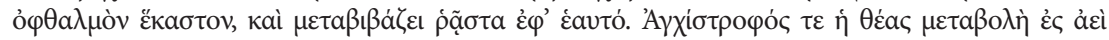

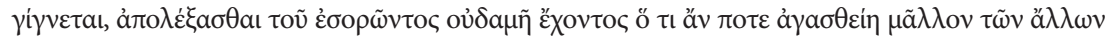

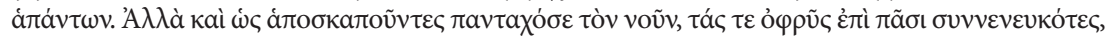

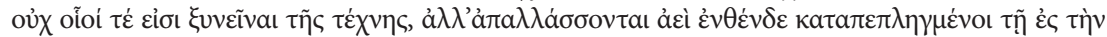
ö $\psi v v$ ả $\mu \eta \chi \alpha v i a ̣$ (...). (Proc., Aed. 1.1.47-9)

Tra le forze che contribuiscono ad accrescere questo fenomeno e a determinare il carattere delle descrizioni e la scelta delle immagini, se ne può cogliere una valida soprattutto in ambito cristiano: la tensione della narrazione, che rappresenta visivamente ciò che non ha realtà materiale $\mathrm{e}$ raffigura l'immaterialità del divino, mentre il simbolismo della luce suggerisce immagini di grande efficacia e spiega la frequente presenza di lampade e lucerne. ${ }^{104}$

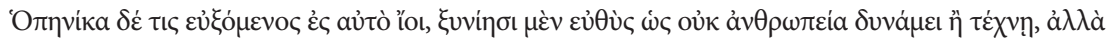

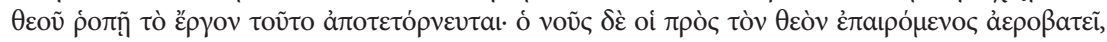

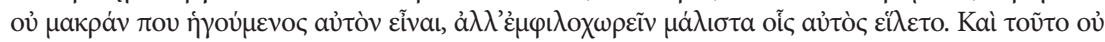

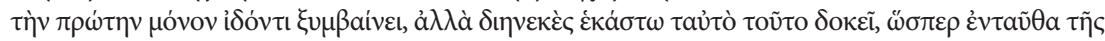

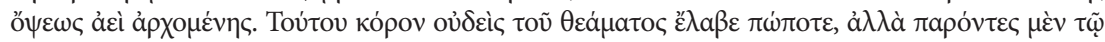

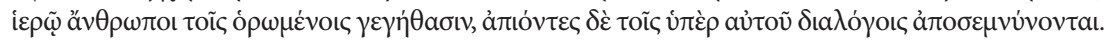
(Proc., Aed. 1.1.61-3)

Aed. 1.1.66-7 "Poco fa era opera divina, ora è frutto di volizione e determinazione umana" (ID.,

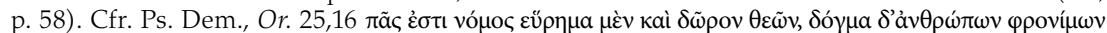
che, definendo così la legge, sembra riprendere quanto dice Procopio della chiesa di Santa Sofia.

${ }_{103}$ "Tutti questi dettagli, messi insieme in alto incredibilmente, sospesi gli uni con gli altri e sostenuti soltanto alle parti molto vicine, producono un'armonia unica e straordinaria dell'opera, e non permettono agli osservatori di soffermare troppo la vista su un punto solo, ma ciascuno attira l'occhio, e lo attrae molto facilmente a sé. La direzione degli occhi si cambia continuamente, poiché lo spettatore non sa selezionare in nessun luogo quale dettaglio voglia mai ammirare più di tutti gli altri. Ma sebbene girino dovunque la loro attenzione, aggrottando le sopracciglia verso tutti i dettagli, gli spettatori non sono capaci di capire la tecnica, ma sempre si allontanano da qui sbigottiti dall'incapacità di capire la visione. (...)". La traduzione è dell'autrice di questo articolo.

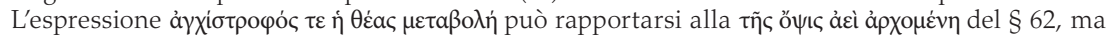
qui è riferita ad elementi architettonici, lì alla decorazione musiva, anche se entrambe offrono la percezione dell'effetto dell'opera sull'osservatore. Questi paragrafi costituiscono una pausa nello svolgimento simile a quella proposta a $\S \S 12-16$.

${ }^{104}$ Cfr. Proc., Aed. 1.1.29-30.

105 "Quando qualcuno entra in questa chiesa per pregare, capisce subito che non è per la capacità o l'abilità dell'uomo, ma per influenza di Dio, che quest'opera è stata magnificamente lavorata: la sua mente, sollevandosi verso Dio, si innalza in alto, credendo che Egli non è lontano, ma che si trattiene volentieri soprattutto in questi luoghi che Egli stesso ha scelto. Di questo spettacolo nessuno ha mai avuto sazietà, anzi quando sono presenti nella chiesa gli uomini si allietano di ciò che vedono, e quando se ne allontanano traggono piacere dal parlare di essa". La traduzione è dell'autrice di questo articolo. Cfr. Aed. 1.1.5 e 22. In questo passo Procopio ha fuso citazioni e reminiscenze neotestamentarie, quali Atti degli Apostoli 17,27 (discorso di S. Paolo all'Aeropago) o Lettera ai Colossesi 1,19 con le molteplici occorrenze veterotestamentarie in merito al divino "abitare' nel suo "popolo eletto", nel suo "tabernacolo", "nella sua terra". Il verbo ảe $\rho \circ \beta a \tau \varepsilon ́ \omega$, di 


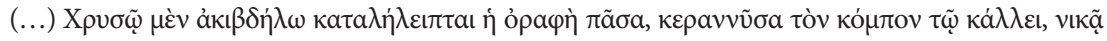

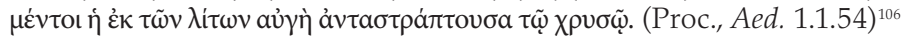

La rappresentazione di entità spirituali attraverso personificazioni, che hanno alle spalle modelli classici, è variamente resa. Si può, infatti, realizzare sia riducendo l'immateriale a materiale, e quindi trasformando entità spirituali in persone o cose dall'aspetto concreto, sia meditando sulla realtà materiale per vederne i significati che la trascendono. Diversi sono i modi in cui si esprimono i procedimenti di allegorizzazioni. Il primo metodo, un tipo di discorso allegorico, proprio per la necessità di rendere perspicui i concetti che si esprimono attraverso le immagini, si caratterizza per una grande capacità descrittiva e per una notevole precisione e ricchezza di particolari. E queste possono tendere allo stereotipo, come quando si vuole cogliere nella realtà un valore esemplare, ma l'accumulo di particolari finisce col ricondurre al generico. Il secondo metodo è comprensibile alla luce di quanto ritiene Basilio (Hexaem. 1.7.3). Il mondo è un'opera d'arte offerta alla conoscenza di tutti e spesso contemplare lo divinae specimen operationis (Ambrogio) significa contemplare il Creatore. La riflessione sulle cose conduce a Lui, perché consente di scorgere, dietro alla materia, aspetti simbolici e perché la contemplazione della bellezza si fa preghiera di lode. Procopio, ponendo una particolare cura nel sottolineare l'uso di materiali e nel descrivere minuziosamente la struttura della chiesa, opera voluta dall'imperatore in quanto sovrano scelto da Dio, sembra fondere entrambi i metodi di resa delle entità sovrannaturali: la precisione nei particolari per esprimere determinati concetti e la conoscenza di Dio attraverso la conoscenza del mondo.

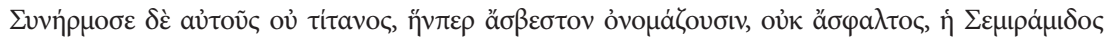

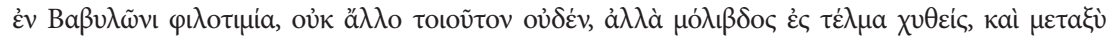

illustre ascendenza aristofanea (Aristoph., Nub. 225) - come ricorda A. Cameron (1985, 35) -, si riferisce alla mente che "vaga per l'aere". Esso è rifunzionalizzato al contesto cristiano, perdendo la chiave comica che aveva in Aristofane che lo aveva messo in bocca a Socrate entrante in scena; in tal modo innalza il tono stilistico del passo e ricorda un passo degli Anecdota $(13,11)$ contro Giustiniano in uno dei passi che lo colpiscono con più ironia. Cfr. anche Proc., Bell. I 25,8 (le vane aspettative di Giovanni il Cappadoce) e Proc., Anec. 20,22 (alterigia del quaestor Costantino). Il tema della "contemplazione insaziabile" è presente anche nella Descrizione della chiesa di S. Sofia di Paolo Silenziario (vv. 296-9). Cfr. Proc., Bell. VII 1,6 (elogio di Belisario dopo la conquista di Ravenna, descrivendo l'ammirazione di cui gode presso i Costantinopolitani) e Proc., Anec. 11,3 (insaziabilità di Giustiniano per le altrui ricchezze e l'omicidio). Si veda Cameron 1985, 35 et al.

${ }_{106}$ "L'intero soffitto, che aggiunge gloria alla bellezza, è rivestito di oro puro; trionfa certamente la luce riflessa delle pietre che risponde con lampi d'oro". La traduzione è dell'autrice di questo articolo. In questo passo è presente una grande attenzione alla luce riflessa dei marmi, che potrebbe definirsi un Leitmotiv di Procopio: qui i marmi si impongono rispetto all'oro, altrove rispetto alla luce riflessa (I 4,5 SS. Sergio e Bacco; I 4,25 S. Acacio; I 6,6 Arcadiane). 


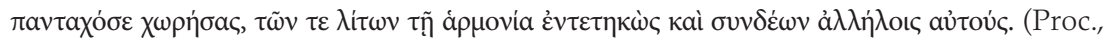
Aed. 1.1.53) ${ }^{107}$

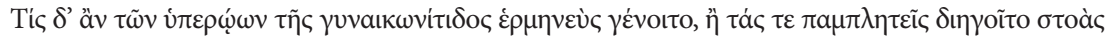

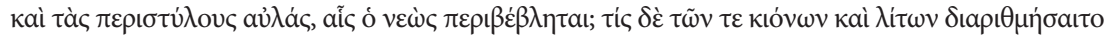

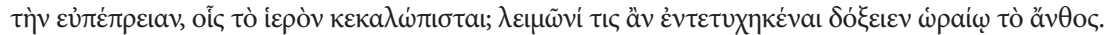

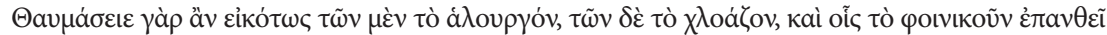

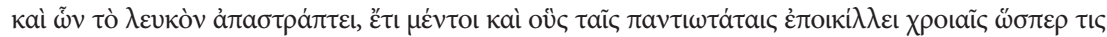

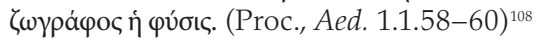

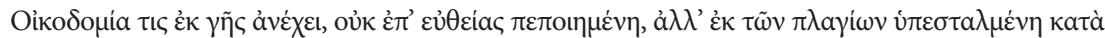

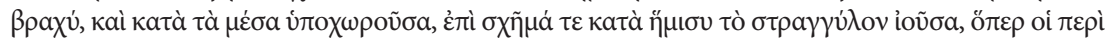

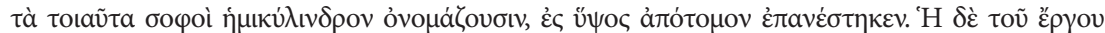

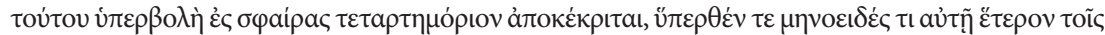

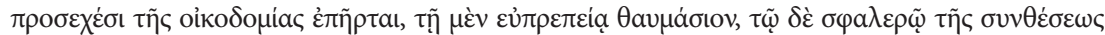

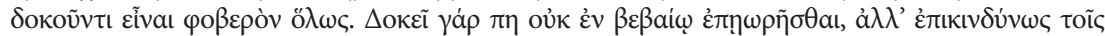

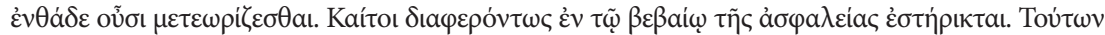

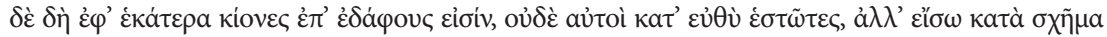

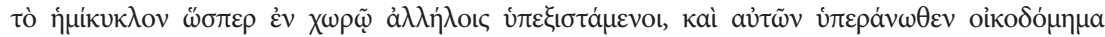

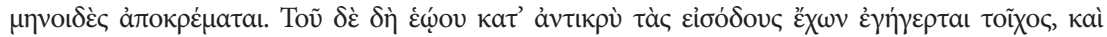

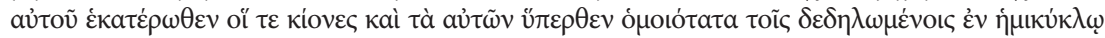

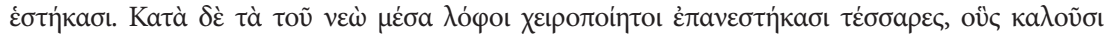

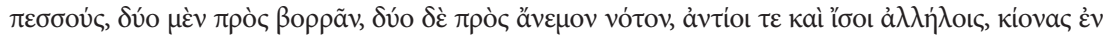

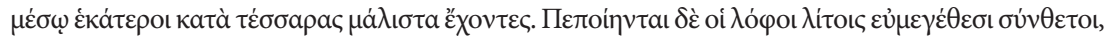

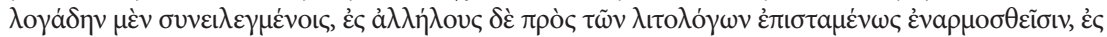

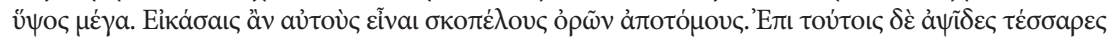

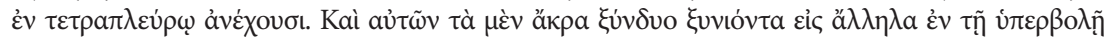

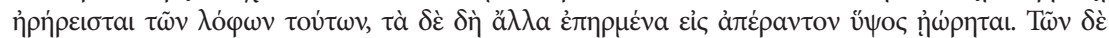

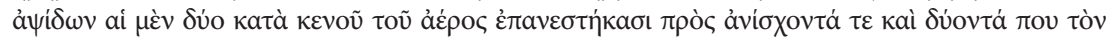

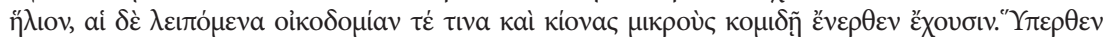

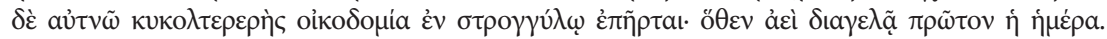

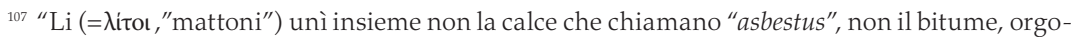
glio di Semiramide a Babilonia, né nessun altro materiale del genere, ma il piombo colato negli interstizi, che si è diffuso in ogni spazio intermedio, si è indurito nelle giunture delle pietre, legandoli gli uni agli altri". La traduzione è dell'autrice di questo articolo. Procopio prende le distanze

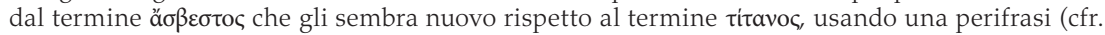
Bell. VI 27,20). La regina di Babilonia è menzionata negativamente in Anec. 1,9 come paradigma di dissolutezza; il rapporto tra Semiramide e il bitume sembra derivare dalla aristia che si legge in Diodoro Siculo (II 11-14) ma si veda anche Strabone (Geografia XVI 1,15).

108 "Ma chi potrebbe descrivere le gallerie del settore femminile, o enumerare i molti porticati e le navate laterali con colonne, dai quali la chiesa è circondata? Chi potrebbe raccontare la bellezza delle colonne e delle pietre, con le quali la chiesa è adornata? A qualcuno potrebbe sembrare di essersi imbattuto in un prato in piena primavera con il suo fiore. Infatti egli potrebbe certamente meravigliarsi del porpora di alcuni, del verde di altri, di quelli su cui appare il rosso e di quelli su cui brilla il bianco, e ancora naturalmente di quelli che la natura, come un pittore, rende variegati con i suoi più contrastanti colori". La traduzione è dell'autrice di questo articolo. Il passo suggerisce che la cromia dei marmi è intesa come brillantezza di colori e che la Natura dipinge i marmi come il pittore dipinge la sua pittura e i rivestimenti marmorei di Santa Sofia sono intesi non come un artificio, ma come un'opera della natura (Natura omnium artifex, Plinio, Hist. II 1,3). Cfr. Libanio, Prog. XII 24,1 (=p. 527,8-10 Förster) e Nicolao Retore, Prog. 12,7 (= p. 406, 26-8 Walz).

Let. Cláss., São Paulo, v. 19, n. 1, p. 3-42, 2015 
'Y

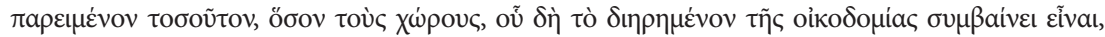

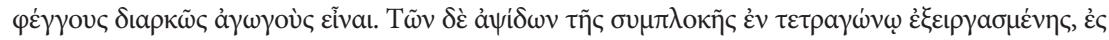

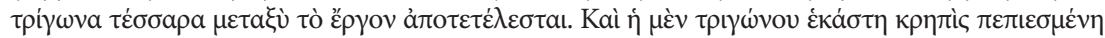

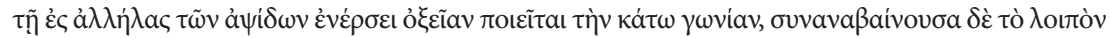

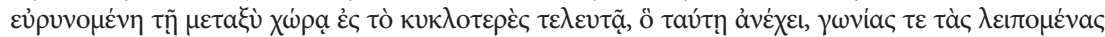

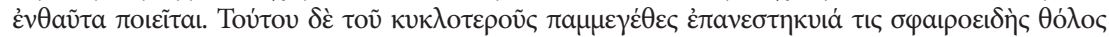

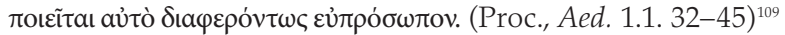

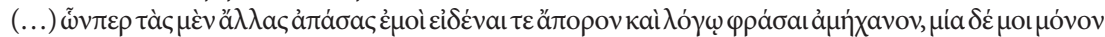

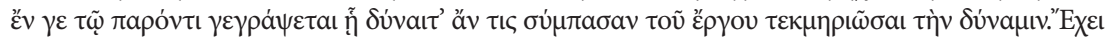

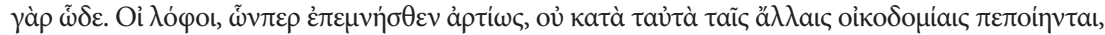

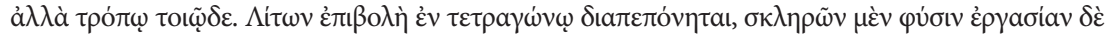

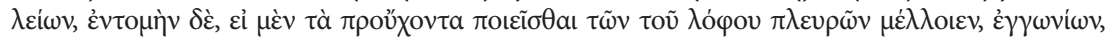

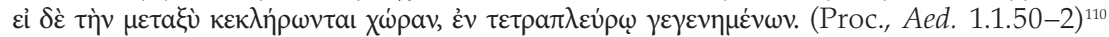

\footnotetext{
109 "Una costruzione si eleva in alto dalla terra, non prolungata in linea diritta, ma curvandosi a poco a poco ai fianchi, e ritirandosi nel mezzo, creando la forma di un semicerchio, che gli esperti di queste materie chiamano 'mezzo-cilindro' e si innalza ad un'altezza incredibile. La parte superiore di questa struttura finisce, separandosi, nella quarta parte di una sfera; sopra questa, sulle parti delimitanti l'edificio, si erge un'altra struttura in forma di mezzaluna, meravigliosa per la sua bellezza, ma a causa dell'apparente insicurezza della sua costruzione veramente impressionante. Infatti sembra in certo qual modo fluttuare su una base, ed essere sollevata in alto pericolosamente per coloro che sono all'interno. A dire il vero essa è appoggiata egregiamente in sicurezza su una base ferma. Da un lato vi sono colonne fissate al pavimento: queste non si innalzano in linea retta, ma verso l'interno a forma di semicerchio, confondendosi le une con le altre come in una danza corale, e sopra di esse è sospesa è sospesa una struttura a forma di mezzaluna. Sul lato opposto a quello orientale, si alza un muro dove sono gli ingressi, e ai due lati di questo sorgono in un semicerchio le colonne e la struttura sopra di esse, che sono molto simili a quelle già descritte. Al centro della chiesa sorgono quattro sporgenze artificiali che chiamano 'pilastri', due a nord e due a sud, opposte e uguali le une le altre, avendo ciascuna coppia al centro solo quattro colonne. Le sporgenze sono composte di pietre di considerevole grandezza unite insieme, accuratamente scelte, abilmente alloggiate le une con le altre dai muratori, ad altezza elevata. Sembrerebbero essere pezzi di roccia tagliati dalle montagne. Da queste, sorgono quattro arcate disposte in un quadrato, le cui estremità, andando a due a due, sono saldate insieme sulla cima di queste sporgenze; le altre parti invece sorgono elevandosi a un'infinita altezza. E mentre due degli archi quelli a oriente e quelli a occidente s'innalzano nell'aria vuota, quelli restanti hanno esattamente sotto di essi una costruzione e piccole colonne. Sopra di questi si trova una struttura circolare di forma cilindrica; attraverso cui la prima luce del giorno sempre sorride. Infatti essa domina, credo, su tutta la terra; la struttura è interrotta per brevi tratti, essendo stato lasciato intenzionalmente tanto spazio, da creare, laddove l'edificio presenta una fenditura, sufficienti canali di luce. Poiché gli archi sono stati costruiti sì da formare un quadrato, la struttura produce nel mezzo quattro triangoli. La base di ciascun triangolo, ristretta nell'intrecciarsi degli archi gli uni con gli altri, rende acuto l'angolo più basso; risalendo su e ampliandosi nella facciata intermedia, finisce nel segmento di un cerchio, che esso perciò sostiene, e forma i rimanenti angoli in quel punto. Eretta sopra questo cerchio l'enorme cupola sferica rende l'opera straordinariamente bella". La traduzione è dell'autrice di questo articolo. Il termine $\gamma \omega v$ ía è un vocabolo tecnico usato nella Geometria di Euclide per indicare l'angolo di una figura piana o solida, mentre nel linguaggio comune significava qualsiasi tipo di angolo interno o esterno, una giunzione tra parti diverse, le quattro sezioni del compasso, uno spazio chiuso

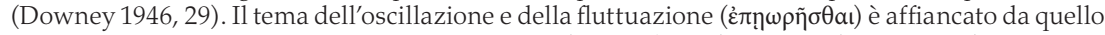

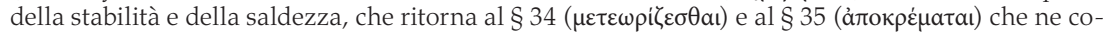
stituiscono la klimax con riferimento alla cupola dorata per poi proseguire ai $\S \S 50$ e $69-78$.

110 " $(. .$.$) è per me difficile comprendere tutti i meccanismi ed è impossibile spiegare a parole;$ per il presente ricorderò solo uno di essi, dal quale si può riconoscere tutta la solidità dell'opera. Esso è questo. I pilastri, che ho menzionato poco fa, non sono costruiti allo stesso modo delle altre
} 


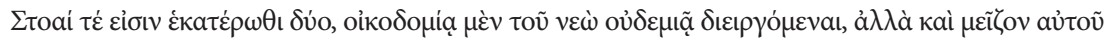

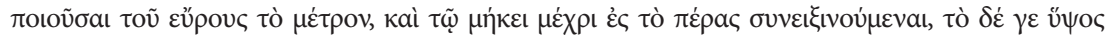

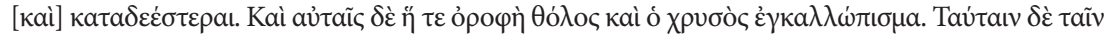

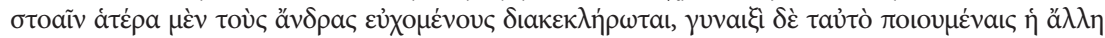

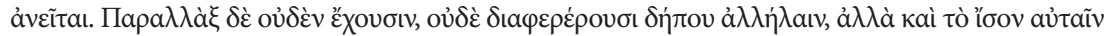

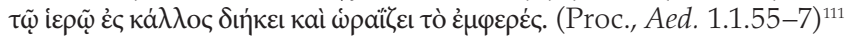

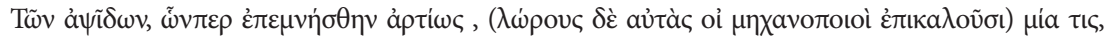

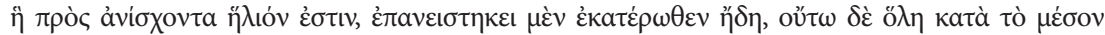

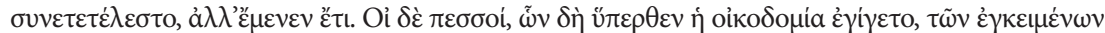

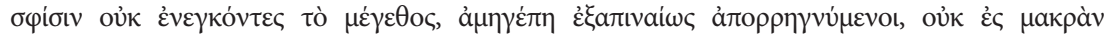

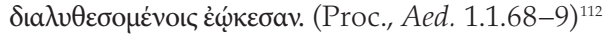

E a tale conoscenza del mondo si giunge attraverso l'esplorazione della realtà, che è esplorazione delle possibilità del linguaggio. Il risultato di questa osservazione del mondo rimanda ad un atteggiamento fortemente intellettualistico ${ }^{113}$ nel quale sono rintracciabili i modelli fondamentali della formazione dell'autore. Infatti l'uso delle fonti, delle citazioni letterarie, che sembrano a prima vista puramente "erudite", risponde molto spesso ad una logica che individua la struttura delle opere di Procopio. ${ }^{114}$ I riferimenti a Omero $^{115}$ e al Senofonte della Ciropedia ${ }^{116}$ o il richiamo sistematico alla serie di exempla virtutis, propri della tradizione romana antica, costituiscono il legame che Procopio ha con i modelli della sua formazione.

Anche nell'attenzione al dettaglio e nella ricchezza dei colori, si rivela l'impronta della istruzione che abitua all'uso di determinate parole "che sono come i colori per il pittore ${ }^{\prime \prime 117}$ : descrivere, quindi, significa mostrare il

costruzioni, ma in questa maniera. Le file di mattoni sono poste in un quadrato: i mattoni duri di natura, ma lisci di lavorazione, erano tagliati, se erano destinati a formare gli spigoli dei lati del pilastro, ma se cambiavano per essere assegnati allo spazio in mezzo agli angoli, erano tagliati a rettangolo". La traduzione è dell'autrice di questo articolo.

111 "Ci sono due porticati nell'una e nell'altra parte, non separati in nessun modo dalla struttura della chiesa, ma che creano anche una maggior misura della sua larghezza, e che si estendono fino alla fine per la sua intera lunghezza, mentre in altezza sono inferiori. Hanno anche essi il tetto a cupola e le decorazioni d'oro. Uno di questi due porticati è stato assegnato agli uomini che pregano, l'altro è riservato alle donne che svolgono la medesima attività. Ma non hanno niente di diverso, né certamente sono differenti gli uni dagli altri in nessun modo, ma equamente servono alla bellezza della chiesa e similmente l'adornano". La traduzione è dell'autrice di questo articolo.

112 "Uno degli archi che ho menzionato poco fa, (gli architetti li chiamano 'loroi') che si trova a oriente, era già stato innalzato dall'uno e dall'altro lato, ma non era stato ancora tutto completato al centro, e aspettava ancora. I pilastri, sui quali la struttura era stata eretta, non sopportando il peso che gravava su di essi, da un momento all'altro spezzatisi, parevano sul punto di crollare presto". La traduzione è dell'autrice di questo articolo.

${ }^{113}$ Cfr. Gualandri 1994, 339.

${ }^{114}$ Cfr. Maisano 1995, 36.

${ }^{115}$ Ad esempio in Proc., Aed. I, 1.15.

${ }_{116}$ Cfr. Proc., Aed. I, 1.13. Cfr. Lexicon Suidae (X $47=$ III p. 494,30 Adler).

${ }^{117}$ La similitudine è di I. Gualandri (1994, 340). 
possesso di un lessico duttile e vario. Talvolta nella frase il termine spicca ancora di più, e di qui si spiega la tendenza tipica dell'età tardoantica, che ama gli elenchi eruditi soprattutto nomi geografici, materiali preziosi, personaggi storici e simili, che diventa un pretesto per ostentare conoscenza di vocaboli tecnici, subordinandoli totalmente al lessico. Inoltre, l'uso di un linguaggio erudito nasconde spesso l'intenzionalità dell'opera e, quindi, la sua perspicua attribuzione ad un determinato genere letterario sebbene in essa vi siano elementi che ne sottolineano un aspetto preciso, come nel caso dell'elemento ecfrastico non unico, ma indubbiamente presente, nella descrizione di Procopio della chiesa.

La chiesa è caratterizzata dalla struttura della cupola, concepita in modo da permettere l'apertura di quaranta finestre che inondano di luce l'interno, e essa appare sospesa sulla navata centrale.

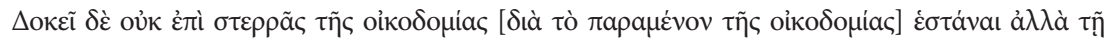

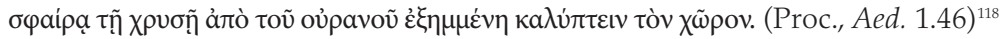

Lo spazio uranico si espande, digradando nelle semi-cupole insieme con l'armonia delle proporzioni, la suprema Divina Armonia, la stessa cui il Grande Costantino aveva dedicato l'ottagono d'Oro annesso al palazzo imperiale di Antiochia. La potenza e la funzione delle strutture erano annullate dagli effetti della luce sugli intagli della decorazione architettonica, sui capitelli dalle forme innovative, sugli intrecci di foglie d'acanto, sui marmi delle colonne e sui rivestimenti fino ad essere riflessa dalle superfici equoree della pavimentazione. "Luce splendida fulgebis ${ }^{191}$ ", luce che irradierà verso le parti del mondo: la luce della divina Sapienza, della Haghia Sophia, ${ }^{120}$ che illumina le menti dell'imperatore e del patriarca, i poteri che si incontrano in uno spazio cerimoniale e simbolico, teofanico e epifanico, metafora architettonica del rapporto fra la divinità e l'impero universale. ${ }^{121}$

\footnotetext{
118 "Ma non sembra elevarsi su una costruzione solida [a causa della debolezza della costruzione] ma coprire lo spazio con la sua cupola dorata sospesa dal cielo". La traduzione è dell'autrice di questo articolo. In questo passo è evidente la metafora, che sottolinea il carattere come aereo

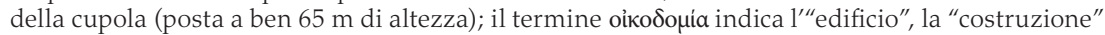
(con questo significato, cfr. Plat., Leg. 758 c, 759 a, 804 c); il termine $\sigma \varphi \alpha$ i. $\rho$, invece, è propriamente "palla, sfera, globo", qui è usato in senso tecnico di "cupola" in quanto ha forma sferica nella parte superiore sebbene sotto sia cava poiché poggiante sui pilastri laterali della costruzione. Il termine è reso da Liddell-Scott-Jones : "ball, any globe, sphere" (Lexic. vol. II, p. 1738).

${ }^{119}$ TOBIA, 13.18.

${ }^{120}$ Per un approfondimento sulla bellezza della luce che sostituisce quella della forma e dei suoi riflessi in Procopio di Cesarea e in Paolo Silenziario: Cfr. Hangstrom 1958; Roberts 1985, 73-6.

${ }^{121}$ L'interpretazione dello spazio basilicale secondo una metafora architettonica è di E. Concina (2002, 62).
} 


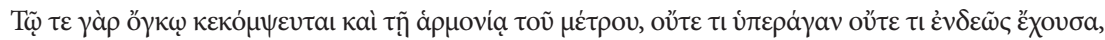

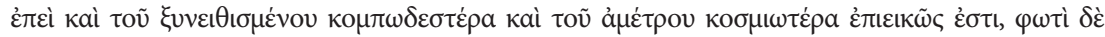

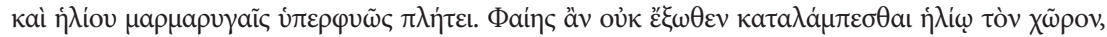

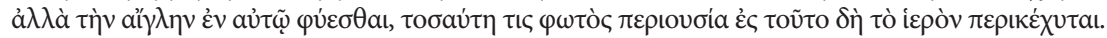
(Proc., Aed. 1.29-30) $)^{122}$

L'intento dell'autore di lodare l'imperatore è nascosto dietro la citazione di dettagli che egli offre al lettore, il quale, da solo, deve rendersi conto dell'importanza di Giustiniano nella riedificazione della chiesa: non è possibile enumerare precisamente gli oggetti preziosi presenti nella

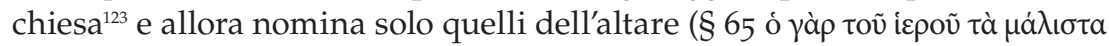

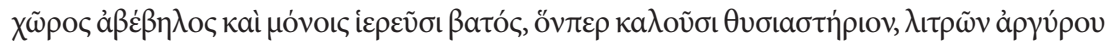

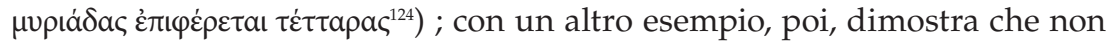
solo con il denaro, speso in materiali preziosi, l'imperatore edificò la chiesa

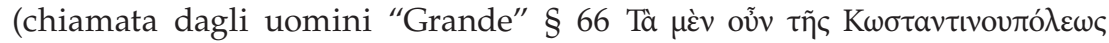

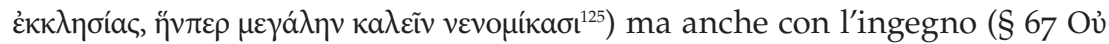

\footnotetext{
122 "Infatti è adornata dalla maestà e dall'armonia delle proporzioni, non avendo né nulla di troppo, né nulla di troppo poco, poiché essa è assai magnifica del consueto e più regolare di ciò che è smisurato, ed è straordinariamente piena di luce e dei riflessi dei raggi del sole. Si potrebbe affermare non che il luogo sia illuminato dall'esterno dal sole, ma che la luce del sole sia generata in esso, tanta è l'abbondanza di luce che si riversa in questo santuario". La traduzione è

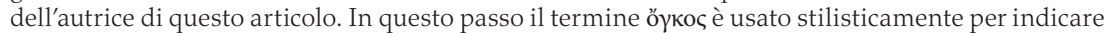
"magnificenza, vanto, maestà" (cfr. anche Long., Subl. 12.3) "weight, dignity, pride, to the style loftiness, majesty" (LSJ, Lexic. vol. II, p.1197); áphovía è termine tecnico per indicare l'armonia delle proporzioni di un complesso (cfr. anche Ps. Phoc. 102); $\mu$ ćtрov è "la giusta misura" (cfr. Pind. Nem. 11, 47); ípòvè "tempio, luogo sacro" qui "chiesa" come luogo di culto e preghiera (il termine tempio è preferito da P. Lamma $(1950,48)$. Attraverso una litote di due espressioni, Procopio afferma che sembra sia la luce del sole a generarsi nella chiesa mettendo in evidenza la luminosità dell'interno di essa permessa grazie alle numerose finestre.

${ }^{123}$ Proc., Aed. I 1.64 in cui sono rilevanti: il termine vaó ‘ "tempio, chiesa" (cfr. Eus. Hist. Eccl., X,2.1), "temple, immost part of a temple, shrine containing the image of the God" (LSJ, Lexic.

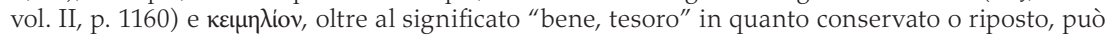
indicare anche "reliquia" (cfr. Cyr. Euthym. 48).

124 "Lo spazio del santuario più sacro e accessibile solo ai sacerdoti, che essi chiamano 'altare' è abbellito con quarantamila pezzi d'argento". La traduzione è dell'autrice di questo articolo. Cfr. E. Stein (1949, 459-60), che afferma che 40.000 libbre di argento dovevano equivalere a circa 160.000 soldi aurei $=127.000 \mathrm{~kg}$. A quarantamila libbre di argento ammontava anche il costo sostenuto dal re di Roma Tarquinio il Superbo per un'altra impresa edificatoria: la costruzione delle fondamenta del tempio di Zeus Capitolino, secondo quanto riferisce Plutarco nelle Vite Parallele

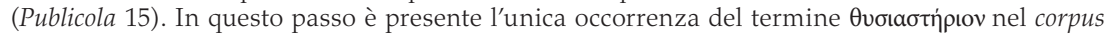
procopiano che indica "altare" in quanto derivante da $\theta v \sigma i \alpha \sigma \mu \alpha$ che è la "vittima sacrificale" o "offerta sacrificale"; qui l'autore ricorre ad una perifrasi di "distanziamento" dalla terminologia tecnica cristiana (cfr. Cameron1985, 35 et al.).

125 "La chiesa di Costantinopoli che gli uomini hanno l'abitudine di chiamare 'Grande'". La traduzione è dell'autrice di questo articolo. Socrate di Costantinopoli (Hist. Eccl. II 16,16= p. 109,9-10 Hansen) afferma che "Grande Chiesa" fu il primo nome dell'edificio del IV secolo; la denominazione Sofia (poi Santa Sofia) è ricordata da lui come espressione di uso corrente al suo tempo, cioè di oltre un secolo anteriore a Procopio, mantenuta nel corso degli anni come testimonia costantemente Giovanni Malala, storico antiocheno contemporaneo di Procopio.
} 


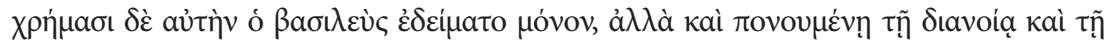

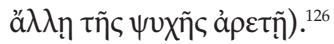

L'opera di Procopio, scritta come un panegirico dell'imperatore, non celebra la virtus esemplare degli architetti, pur ricordandone le persone, ma attribuisce il merito maggiore all'imperatore stesso, minimizzando il ruolo dei suoi sottoposti. ${ }^{127}$ Così, il superamento delle difficoltà del cantiere è attribuito allo stesso Giustiniano, cui Antemio e Isidoro "privi di speranza nella

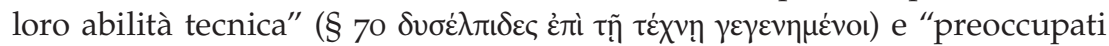

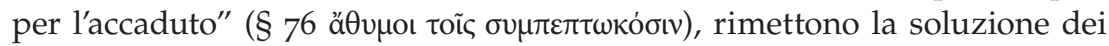
problemi manifestatisi e apparentemente insuperabili. All'interno dell'opera, quindi, sono menzionati solo cinque architetti ${ }^{128}$ contemporanei: Antemio e Isidoro, ${ }^{129}$ Crise di Alessandria, ${ }^{130}$ Giovanni di Bisanzio, ${ }^{131}$ Isidoro il Giovane $^{132}$ e Apollodoro di Damasco, che visse al tempo di Traiano. ${ }^{133}$

Questa abitudine è comprensibile in una società nella quale il sovrano riassumeva in sé l'insieme delle autorità religiosa e politica e quindi era ufficialmente attribuito a lui ogni iniziativa di costruzione di qualunque opera pubblica di carattere monumentale. ${ }^{134}$ Come sottolinea Diehl, "an Emperor, by definition, possesses a universal competence". 135 Tuttavia nel

\footnotetext{
${ }_{126}$ “Ma non fu solo con il denaro che l'imperatore l'edificò, ma anche con l'ingegno della mente e ogni risorsa dell'anima, come io subito dimostrerò". La traduzione è dell'autrice di questo articolo. Cfr. Agapeto (Esposizione dei capitoli parenetici, § 55) che sottolinea che il sovrano deve essere "perspicace, soprattutto nei giudizi sulle questioni più ardue" (trad. Cavarra 1990).

${ }^{127}$ Cfr. Downey 1947, 190 ss.

${ }^{128}$ Cfr. Downey 1948 101, 102, 105: "The conception now generally prevailing of the function of Byzantine architects and of the character of their work has been based, quite simply, on the circumstance that these men are generally called $\mu \eta \chi$ Хavıкó (= "engineer" in Liddell-Scott-Jones'

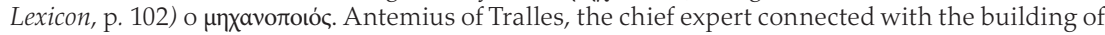

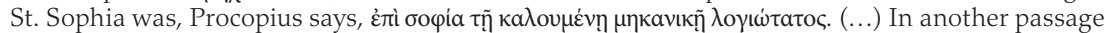
Procopius calls colleague $\mu \eta \chi \propto$ vолоเóc. Elsewhere he refers to Antemius and his colleague Isidorus

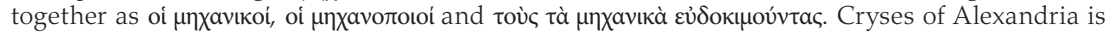

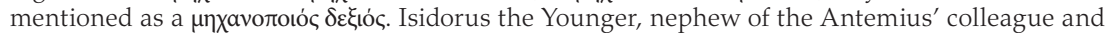
John of Byzantium are $\mu \eta \chi a v o \pi$ toi. (...) Procopius, who calls contemporary figures $\mu \eta \chi a v ı$ เi and

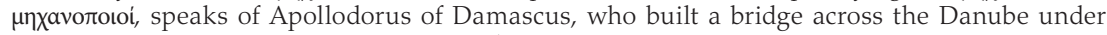
Trajan, as "à $\rho \chi \imath \varepsilon \dot{\kappa} \tau \omega v "$ of the wholework" (Aed. IV 6.13- questa è l'unica occorrenza della parola

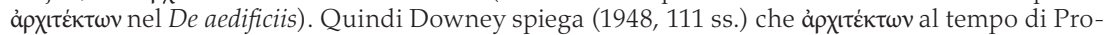
copio indicava un ruolo inferiore a $\mu \eta \chi a v ı$ có, al contrario del periodo traianeo in cui era il più

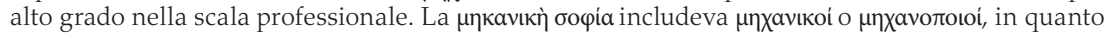
"science of mechanics", conoscenza di coloro che avevano completato il corso di studi ed erano competenti in disegno tecnico, progetti e costruzione. Cfr. Pappi Alexandri Collectionis quae supersunt, ed. F. Hultsch III, Berlin 1876-1878, pp. 1022-4.

${ }^{129}$ Aed. I, 1. E inoltre per ulteriori fonti antiche si veda Downey 1948, 112-14.

${ }^{130}$ Aed. II 3.2.

${ }^{131}$ Aed. II 8.25 .

${ }^{132}$ Aed. II 8.25 .

${ }^{133}$ Aed. IV 6.13.

${ }^{134}$ Cfr. Downey 1938, 1-15 e 299-311; Charlesworth 1943, 1-10.

${ }^{135}$ Manuel d'Art Byzantin I, Paris 1925-26, p. 155.
} 
momento in cui gli architetti sottopongono il problema dell'instabilità dei pilastri all'imperatore e poi delle colonne, Procopio, riconoscendo che egli non era un architetto, riconduce la sua intuizione tecnica a Dio che lo ha

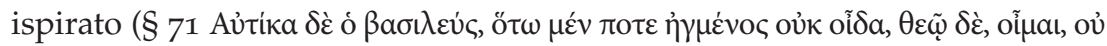

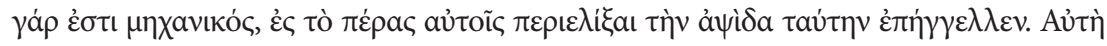

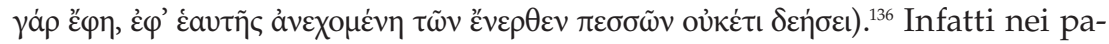
ragrafi finali ${ }^{137}$ del $1^{\mathrm{o}}$ capitolo sono espressi tutta la concezione del potere imperiale nel vi secolo e i caratteri della figura divina dell'imperatore ${ }^{138}$.

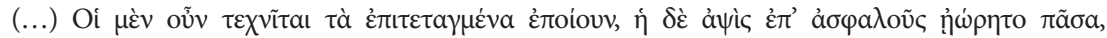

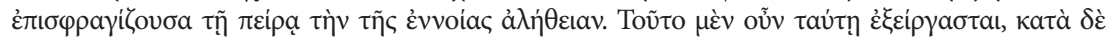

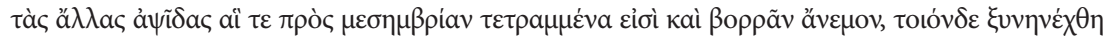

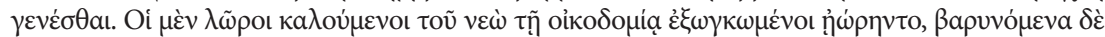

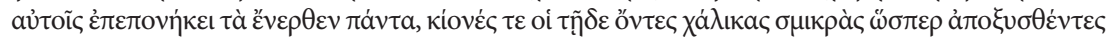

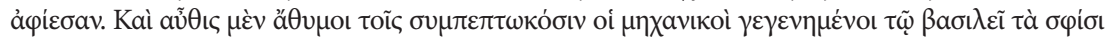

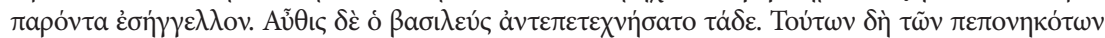

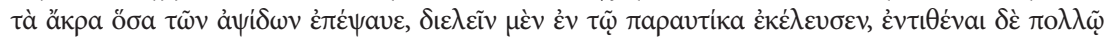

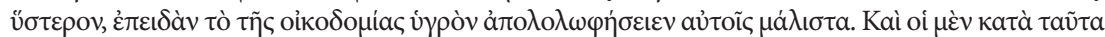

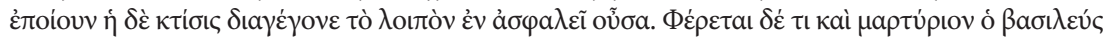

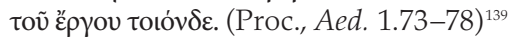

136 "Subito l'imperatore, spinto da non so cosa, da Dio, credo, (infatti egli non era un architetto)
comandò loro di portare questa curva fino al limite "Quando si sosterrà da sé" disse "non avrà più
a lungo bisogno dei pilastri sottostanti"". La traduzione è dell'autrice di questo articolo. La tem-
pestività dell'azione di Procopio si pone in simmetria con la sua lentezza all'ira verso i congiurati
( $§ \S 10$ e 16). L'enfasi sulla prontezza nell'azione ha precedenti illustri anche nel mondo classico
(es. Ps. Isocrate, A Demonico 34 (= p. 20,2 Mandilaras) e Proc., Anec. $6.26-8$ dove vengono uccisi
Amantio e Vitaliano, ritenuti pericolosi per la loro ascesa). La citazione di una frase pronun-
ciata da Giustiniano (unica occorrenza nel corpus procopiano) vorrebbe mostrare sia la precisione
dell'enunciazione diretta, sia la preveggenza dell'imperatore, presenti anche in Aed. II 7,9 e III 1,3 (cfr. Nov. 40 -535 d.C.; Ed. $13-539$ d.C.).

${ }^{137}$ Aed. I, 1. 71-8.

${ }^{138}$ Cfr. Ravegnani 2008a, 11-14, 18-20.

139 "(...) Dunque gli operai eseguivano gli ordini dati, e l'intero arco rimase sollevato in sicurezza, confermando con la prova la giustezza della sua idea. Dunque questo arco fu completato in questo modo, ma per gli altri archi che erano posti a sud e a nord avvenne questo. I cosiddetti "loroi" erano stati eretti, facendo da portanti alle strutture della chiesa, ma tutto era stato collocato sotto il loro peso, e le colonne che stavano lì gettavano del come se fossero piallate. E ancora una volta gli architetti, preoccupati da quanto accaduto, portarono il problema all'imperatore. Subito l'imperatore trovò un rimedio a questo. Ordinò di rimuovere subito le parti superiori danneggiate che toccavano le arcate, e di rimetterle indietro molto dopo, una volta che l'umidità della struttura fosse ridotta abbastanza per ricostruirle. Essi eseguirono queste disposizioni e la struttura, restando al sicuro, durò nell'avvenire. Essa è testimonianza dell'opera dell'imperatore". La traduzione è dell'autrice di questo articolo. In questo passo sono numerosi i termini tecnici: ö $\psi$ ıs è "arcata, volta" (cfr. Ps. Eus., PE I, 3.11); il termine $\pi \varepsilon \sigma \sigma o$, "pilastri", propriamente indica "macigni, massi" (di costruzione, cfr. Strab., Geogr. XVI, 1.5; il termine origina l'unica occorrenza del De aedificiis presente nel Lexicon Suidae P 1645 =IV 135,3 Adler), anche se M. L. Fobelli (in Cesaretti 2011, 80) ritiene che esso si riferisca ai puntelli verticali di una centina appoggiata a terra, pur riconoscendo che tale interpretazione è in netto contrasto con il significato di "pilastri" che Procopio gli attribuisce al § 37; il termine $\lambda \tilde{\omega} \rho o t$ indica un tipo di arco ma in Lyd., Mag. II 2 è un tipo di mantello e propriamente indica una striscia di cuoio o una cinghia, tuttavia è inteso 
Procopio loda l'ingegno illuminato dell'imperatore, in quanto ispirato da Dio, ma soprattutto ammira la durevole applicabilità pratica dei

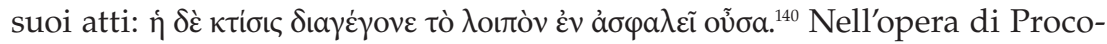
pio la lode dell'imperatore risiede non solo nel sottolineare l'importanza dell'imperatore restauratore dello stato, costruttore di città e di frontiere

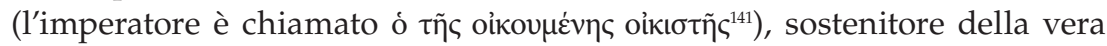
fede, ordinatore delle leggi, nonché portatore della pace nello stato, ma anche nel dimostrare la sua partecipazione attiva ai cantieri. Nel De aedificiis, quindi, diversamente dagli Anecdota, che offrono al lettore l'immagine di un imperatore tiranno non ispirato da Dio, ma quasi demoniaco, l'autore insiste molto sulla figura dell'imperatore Giustiniano, ispirato da divina pietà e soggetto della sua lode, richiamandola all'attenzione del lettore con l'espressione topica "Giustiniano nostro imperatore". ${ }^{142}$ Il sovrano di Costantinopoli è un rappresentante di Dio sulla terra, che occupa un posto importante vicino alla dimensione sovrannaturale rispetto agli uomini ordinari ${ }^{143}$ e in questo modo Procopio si inserisce non solo nella dimensione retorica, ma anche imperiale, della letteratura a lui contemporanea. Infatti l'imperatore, scelto e ispirato da Dio, e i suoi atti di restaurazione e miglioramento dell'impero vennero elogiati dalle opere letterarie celebrative già a partire da Eusebio, autore de Sulla vita di Costantino. ${ }^{144}$ L'impero era voluto da Dio, che aveva eletto il popolo cristiano come depositario della sua volontà $\mathrm{e}$ da Dio proveniva il potere del sovrano di Costantinopoli. Dio sceglieva il sovrano influenzando a suo piacimento i meccanismi umani di elezione, ed era l'unico giudice dell'imperatore. Il Cecaumeno (xII secolo) scrive: "Dio ti ha elevato al potere imperiale di sua mano e ti ha reso un dio terrestre ${ }^{145^{\prime \prime}} \mathrm{e}$ questo sembra fare eco a un'espressione del cerimoniale palatino: "nelle tue mani avendo oggi affidato il potere, Dio ti ha confermato sovrano assoluto

anche come termine tecnico usato in architettura: "arch. lat. lorum, thoug" ("cinghia": LSJ, Lexic. vol. II, p. 1069- Il corsivo è dell'autrice di questo articolo,) inoltre il termine è interessante poiché

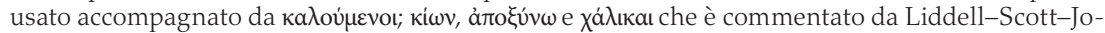
nes "small stones, pebbles, rubbles used in buildings" (Lexic. vol. II, p. 1972). Cfr. Aed. II 3,1-15 dove si racconta che l'imperatore risolve un problema presentatogli da Antemio di Tralle e Isidoro di Mileto dopo l'inondazione di Dara, i cui lavori furono affidati, dopo una consultazione con i

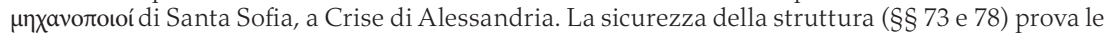
due virtù di Giustiniano, ovvero la fermezza e la preveggenza. La basilica non solo è il prodotto ma celebra la Sapienza divina negli eventi terreni attraverso il rapporto tra Dio e il sovrano.

${ }^{140}$ Proc., Aed. I 1. 78: "(..) e la struttura, restando al sicuro, durò nell'avvenire".

${ }^{141}$ Proc. , Aed. IV 1.17 ("costruttore del mondo").

${ }_{142}$ Proc., Aed. VI 7.17-8; V 2.3; V 5.7.

${ }^{143}$ Questa ideologia che considera il sovrano un eletto di Dio, da lui ispirato nelle imprese grandiose si trova anche in Cor., Iust. II 42 ss. e Eus., Vit. Cost. III 25 ss.

${ }^{144}$ Eus., Vit. Cost. III 25 ss.

${ }^{145}$ Giov. Cec., Strateg. cap.77. Trad. it. a cura di G. Ravegnani (2008, 13). Cfr. North 1998, 274. 
e, sceso dal cielo, il grande duce degli eserciti davanti al tuo volto ha aperto le porte dell'impero ${ }^{146^{\prime \prime}}$. Pertanto in quanto intermediario fra gli uomini e la divinità, e sovrano investito da Dio, la figura dell'imperatore era sacra, così come sacro era tutto quanto gli si connetteva e si riteneva un sacrilegio offenderlo, anche trasgredendo i suoi ordini: sacro il Palazzo, divine le leggi, e di divine sorti gli imperatori defunti. I sudditi dovevano assumere l'obbligo di prestare fedeltà all'imperatore, che ne aveva uno analogo nei confronti della sua chiesa, ma verso il proprio popolo l'imperatore doveva esercitare

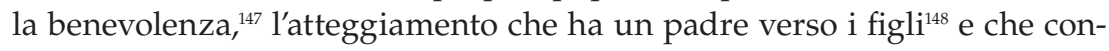
siste nel saper perdonare. Un'altra sua qualità doveva essere l'impassibilità, in forza della quale non doveva lasciar trasparire alcun turbamento dando di sé un'immagine stereotipata. Queste qualità gli derivavano dall'imitazione di Dio: l'impero terrestre doveva imitare nelle forme quello celeste di cui si riteneva fosse espressione e chi in terra deteneva l'autorità era tenuto a imitare Dio, affinché fosse a sua volta imitato dai sudditi così da portarli alla perfezione morale. Imitarlo significava attuarne le virtù proprie di Dio, quali benevolenza, saggezza, potenza, giustizia, previdenza e vivere in uno splendido palazzo che doveva riprodurre la corte celeste..$^{149}$

L'obbiettivo dell'opera di Procopio è, dunque, glorificare l'imperatore protetto da Dio attraverso il catalogo delle opere da lui ordinate ${ }^{150}$ infatti tutto ciò che Procopio descrive è attribuito al solo Giustiniano; ma l'autore, rispondendo ai canoni comuni dei panegirici, dice che è un caso. ${ }^{151}$ Questo è un tema strettamente connesso all'ideologia imperiale. Infatti già nel $\mathrm{v}$ secolo, quando gli eventi e le ondate barbariche posero fine alla diarchia nata con Diocleziano, ${ }^{152}$ lo stato bizantino ereditò intatta tutta la dottrina dell'impero romano universale ed espressione del regno celeste. ${ }^{153}$ Tuttavia

\footnotetext{
${ }^{146}$ Trad. it. a cura di G. Ravegnani $(2008,13)$. Vd. anche Cost. Porf., De cerem. I, 38 (=I, pp-191-6 Reiske; II, pp.1-5, pp. 47-8 Voigt).

${ }^{147}$ Cfr. Proc., Aed. I 1. 10.

${ }^{148}$ Si ricordi l'espressione omerica usata da Procopio, riferendo all'imperatore la caratteristica di

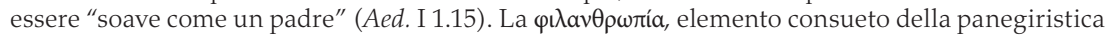
imperiale, era stata anche una qualità di Ciro (cfr. Sen., Cir. I 2,1; VIII 2,1). Cfr. Proc., Panegirico per l'imperatore Anastasio § 7, p.46,170; § 10 p. 48,219; § 25 p. 55,427-40 Matino).

${ }^{149}$ Il legame fra regno terrestre e regno celeste trovava attuazione anche in alcuni temi figurati

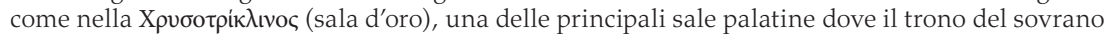
sorgeva sotto un'immagine del Cristo in trono così che al popolo si mostrasse il Re dei cieli e chi da Lui era stato inviato a rappresentarlo in terra. Ne conseguiva che chiunque potesse salire al trono anche se si richiedevano la prestanza fisica e le qualità morali per cui venivano esclusi i mutilati e gli eunuchi.

${ }^{150}$ Cfr. Downey 1950.

${ }^{151}$ Proc., Aed. VI 5.6.

${ }^{152}$ La delicata essenza della diarchia in epoca post- costantiniana è stata tratteggiata da H. M. Jones (1981, 400).

${ }^{153}$ Cfr. Maisano 1995, 15.
}

Let. Cláss., São Paulo, v. 19, n. 1, p.3-42, 2015 
il De aedificiis è diverso nella forma dai panegirici contemporanei e non of-

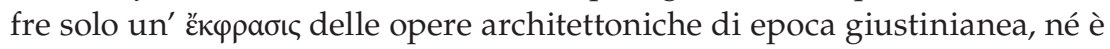
totalmente incentrato su temi imperiali come il panegirico di Corippo ${ }^{154} \mathrm{su}$ Giustino II, o la prefazione al Ciclo di Agazia. ${ }^{155}$ Infatti l'opera di Procopio non è un'opera- documento che si limita a registrare i caratteri degli edifici fondamentali, risultato della politica costruttiva urbana e provinciale di Giustiniano, attraverso descrizioni architettoniche e strutturali.

È un'opera-monumento che presenta una sezione descrittiva, ma è anche un supporto utile all'autore per dimostrare che quegli edifici sono il segno tangibile del potere cristiano dell'imperatore. Egli consegna ai posteri i magnifici edifici giustinianei, che devono essere incredibilmente attribuiti ad un solo uomo ${ }^{156}$ cui è riconosciuto il merito di averne voluto e migliorato la costruzione o la restaurazione.

Il primo capitolo è fondamentale poiché rispecchia proprio questo carattere dell'intera opera. Esso non presenta solo una descrizione della chiesa come quella del poema di Paolo Silenziario sulla restaurata S. Sofia (non è solo un "repository of aestetic ekphrasis"157), ma anche un panegirico politico di Giustiniano. Infatti ai paragrafi di una lunga ěk $\varphi \rho \alpha \sigma \iota \iota^{158} \mathrm{si}$ affiancano molteplici paragrafi intrisi di episodi e lodi soffuse dell'imperatore. Se la lunga descrizione ecfrastica della struttura della chiesa ${ }^{159}$ sembra essere fondamentale nell'economia del racconto, per Procopio è anche necessario rendere chiara la volontà di Giustiniano di costruire grandiose opere e l'abilità nel saperne risolvere i problemi architettonici. ${ }^{160}$ Giustiniano non solo ha voluto la ricostruzione della chiesa, ma ha ricoperto uno ruolo attivo nella risoluzione di problemi legati alla costruzione stessa dell'edificio. L'autore intende mostrare chiaramente i segni di una monarchia voluta e ispirata da Dio. Per questo motivo, dopo essersi spesso distaccato dalla dimensione retorica, di cui la sua opera è espressione, per abbandonarsi a descrizioni ed elenchi di edifici monumentali o difensivi, ${ }^{161}$ ritorna all'elaborazione retorica, dando l'impressione che le sue siano solo digressioni descrittive e che non abbiano un importante sfondo retorico. Tuttavia la sua

${ }^{154}$ Cfr. Cameron 1976a.

${ }^{155}$ AP IV. 3.

${ }^{156}$ Cfr. Proc., Aed. I 1.17.

${ }^{157}$ La definizione è di A. Cameron $(1985,233)$.

${ }^{158}$ Che nel caso dell'opera sembra affievolirsi subito dopo il I libro (cfr. Cameron 1985, 90).

${ }^{159}$ Proc., Aed. I 1.27-66.

${ }^{160}$ Cfr. Roques 1998, 989-1001.

${ }^{161}$ Fra le molte descrizioni di chiese: cfr. Proc., Aed. I 3.3 (chiesa di Blachernae); I 6.5-8 (chiesa dei SS. Cosma e Damiano); V 6.1 (chiesa della Vergine a Gerusalemme); e opere difensive: cfr. PROC., Aed. II 7.2-10 (canale di Edessa). 
è una testimonianza di matrice retorica del governo di Giustiniano, che ne rende chiari i caratteri propri ma anche le contraddizioni. ${ }^{162}$

\section{BIBLIOGRAFIA}

Archi, G. G. 1970. Giustiniano legislatore. Bologna.

Atkinson, J. 2000. "Justinian and the Tribulation of the Transformation." AClass $43: 15-32$.

Belting, H. 2001. Il culto delle immagini. Storia dell'icona dall'età imperiale al tardo Medioevo. Roma.

Brehier, B. 2009. Bisanzio. Vita e morte di un impero. Genova.

Brenk, B. 2003. "Committenza e Retorica del costruire: tecniche, artisti, artisti, artigiani, committenti." In Arti e Storia del Medioevo II. Torino.

Brown, P. 1974. Il mondo tardo antico. Trad. a cura di A. V. Malvano. Torino.

Browning, R. 1986. "Justinien." Dictionary of Middle Ages 7:165-78.

Cameron, A. 1976a. Flavius Cresconius Corippo: in laudem Iustini Augusti minoris. London.

Cameron, A. 1976b. Circus factions. Blues and Greens at Rome and Byzantium. Oxford.

Cameron, A. 1985. Procopius and the Sixth Century. London.

Capizzi, C. 1994. Giustiniano I tra politica e religione. Soveria Mannelli.

Cavarra, B. 1990. “Ideologia politica e cultura fra IV e V secolo." Quaderni della Rivista degli Studi Bizantini 9:25-67.

Cesa, M. 1981. "La politica di Giustiniano verso l'Occidente nel giudizio di Procopio." Athenaeum 59:389-409.

Conant, K. J. 1946. "The First Dome of Ste-Sophia and its Rebuilding." Bulletin of the Byzantine Institute 1:589-91.

Concina, E. 2002. Le arti di Bisanzio. Milano.

Cesaretti, P.; Fobelli, M. L. 2011. Procopio di Cesarea, Santa Sofia di Costantinopoli. Un tempio di luce. Milano.

Charlesworth, M. P. 1943. "Pietas and Victoria: The Emperor and the Citizen." J.R.S. 33:1-10.

Dagron, G. 1984. Constantinople imaginaire. Études sur le recueil des Patria. Paris.

Della Valle, M. 2007. "La Santa Sofia, le Sante Sofie e la 'cattedrale' nel mondo bizantino." In Medioevo: l'Europa delle Cattedrali: Atti del X Convegno Internazionale di Studi (Parma, 19-23 settembre 2006), a cura di A. C. Quintavalle, 155-69. Parma-Milano.

De Maffei, F. 1988. "Edifici di Giustiniano nell'ambito dell'impero." In Centro di Studi sull'Alto Medioevo, 7-23. Spoleto.

Dewing, H. B.; Downey, G. 1940. Procopius of Cesarea, Buildings (De Aedificiis). Londra-Cambridge. (The Loeb Classical Library, 343).

162 “Così l'edificio (...) è meno l'oggetto di una descrizione che il documento di una responsabilità (di Giustiniano) e soprattutto la prova e quasi la testimonianza di un rapporto ; il rapporto tra Giustiniano e la divinità (...) ambiguo e dichiarato, dove le libere determinazioni dell'imperatore si incontrano con il grande disegno divino" (Cesaretti 2011, 51). 
Dolger, F. 1935. "Justinian, Engel an der Kaisertur der Haghia Sophia." Byzantion $10: 1-4$.

Downey, G. 1938. "Imperial Building Records in Malalas." Byz. Zeit 38:1-15,299-311.

Downey, G. 1946. "On Some Post- Classical Architectural Terms." Transactions and Proceedings of the American Philological Association 77:22-34.

Downey, G. 1947. "The Composition of Procopius, De aedificiis." TAPA 78.

Downey, G. 1948. "The Byzantine Architects. Their Training and Methods." Byzantion 18:99-118.

Downey, G. 1950. "Justinian as a builder." Art Bulletin 32:262-6.

Downey, G. Gaza in the Sixth Century. Norman, Okla.

Evans, J. A. S. 1968. "Procopius of Caesarea and the Emperor Justinian." Canadian Historical Association, Historical Papers, 126-39.

Evans, J. A. S. 1970. "Justinian and the Historian Procopius." Greece and Rome 17:217.

Evans, J. A. S. 1996. The Age of Justinian: the circumstances of Imperial power. LondonNew York, Routledge.

Fobelli, M. L. 2005. Un tempio per Giustiniano: Santa Sofia di Costantinopoli e la Descrizione di Paolo Silenziario. Roma.

Fobelli, M. L. 2006. "La recinzione presbiteriale della basilica di S. Sofia a Costantinopoli e il suo programma figurativo." In Ubi neque aerugo tinea demolitur: Studi in onore di L .Pellegrini, a cura di M. G. Del Fuoco. Napoli.

Fobelli, M. L. 2007. "Descrizione e percezione delle immagini acheropite sui marmi bizantini." In Immagine e Ideologia. Studi in onore di Arturo Carlo Quintavalle, a cura di A. Calzona, R. Campari, M. Mussini, 27-32. Parma-Milano.

Foschi, S. 2002. "S. Sofia di Costantinopoli: immagini dall' Occidente." Annali dell'Architettura 16. Vicenza.

Gualandri, I. 1994. "Aspetti dell'ekphrasis tardoantica." In Testo e Immagine nell'Alto Medioevo 41 (15-21 aprile 1993), 301-41. Spoleto.

Hangstrom, J. H. 1958. The Sister Arts. Chicago.

Heisenberg, A. 1912. "Die alten Mosaiken der Apostelkirche und de Haghia Sophia." छ̇́vı , Hommage internat.à l'Univ. nat. de Gréce. Atene.

Impellizzeri, S. 1975. La letteratura bizantina. Da Costantino a Fozio. Firenze-Milano.

James, L. 2007. Art and Text in Byzantine Culture. Cambridge.

Janin, R. 1964. Constantinople Byzantine. Paris.

Jeffreys, E. 2000. "Malalas, Procopius and Justinian's Buildings." AntTard 8:73-9.

Jones, A. H. M. 1981. Il tardo Impero Romano, I-III. Trad. a cura di E. Petretti. Milano.

Kashdan, A.P. 1995. Bisanzio e la sua civiltà. Trad. it. a cura di G. Arcetri. Bari.

Kraft, H.; Gulzow, M.; Werz, I. 1976. La teologia dei Padri. Trad. it. a cura di G. Mura e G. Corti. Roma.

Kautzsch, R. 1936. Kapitellstudien. Berlin.

Krautheimer, R. 1986. Architettura paleocristiana e bizantina, trad. it. Torino.

Lamma, P. 1950. "Paolo Silenziario poeta di S. Sofia e panegirista di Giustiniano." In Ricerche sulla storia e la cultura del VI secolo, 47-70. Brescia, (=1968, in Oriente e Occidente nell'Alto Medioevo, 158-60. Padova).

Lethaby, W. R.; Swainson, H. 1894. The Church of Sancta Sophia, Constantinople: a Study of a Byzantine Building. London-New York. 
Luchetti, G. 2004. Contributi di diritto giustinianeo. Milano.

Mainstone, R. J. 1988. Haghia Sophia. Architecture, Structure and Liturgy of Justinian's Great Church. London.

Mainstone, R. J. 2009. S. Sofia, trad. it. a cura di G. L. Giacone. Milano.

Maisano, R. 1995. Discorsi di Temistio. Torino.

Maiuri, A. 1912. "Cod. Vat. 1823, Fo 95." Byz. Zeitsch. 21:360.

Mango, C. 1978. Architettura Bizantina, trad. it. Milano.

Mango, C. 2004. The Art of Byzantine Empire 312-1453: Sources and Documents. Toronto.

Mango, C. 2006. La civiltà bizantina. Roma.

Maraval, P. 1999. L'empereur Justinien. Paris: Pr. Universitaires de France.

Mazal, O. 2001. Justinian I und seine Zeit: Geschichte und Kultur des Byzantinischen Reiches im 6 Jahrhunddert. Koln-Wien-Bohlan.

Meier, M. 2003. “Die Inszenierung einer Katastrophe: Justinian und der Nika - Aufstand." ZPE 142:273-300.

Meier, M. 2004. Justinian. Herrschaft, Reich und Religion. Munchen. (Trad. it. Giustiniano, Bologna, 2007).

Millet, G. 1923. "La cupole primitive de Ste-Sophie." Revue belge de philologie et d'histoire 2:597-617.

Millet, A. 1947. "Sainte Sophia." Orientalia Christiana 3:596-612.

Mooread, J. 1994. Justinian. London.

Mundell, M. 1998. The Archeological Context of Finds of Silver in and beyond the Eastern Empire. Acta XIII Congr. Intern, Archeol. Crist. (II). Split.

Nardi, E. 1991. Le istituzioni giuridiche romane. Gaio e Giustiniano. Milano.

North, W. 1998. Logos Nouthetikos or Oration of Admonition to an Emperor of the Strategikon (\$77-88). Dumbarton Oaks.

Norwich, J. J. 2000. Bisanzio. Milano.

Osieczkowska, C. 1934. "La mosaique de la Porte Royale à Ste-Sophie de Constantinople et la litanie de tous le Saints." Byzantion 9:41-81.

Padovese, L. 1993. "Monofisismo." Dizionario Enciclopedico Tedesco, 676-7. Roma.

Pescani, P. 1965. "Novellae di Giustiniano." Novissimo Digesto Italiano 11:438-45.

Procopii Caesariensis opera omnia, rec. J. Haury IV De aedificiis, ed. ster. add. et corr. G. Wirth, Lipsiae 1964.

Ravegnani, G. 2008a. Imperatori di Bisanzio. Bologna.

Ravegnani, G. 2008b. Introduzione alla storia di Bisanzio. Bologna.

Roberts, M. 1985. The Jeweled Style. Ithaca-London.

Ronchey, S.; Braccini, T. 2010. Il romanzo di Costantinopoli. Guida letteraria alla Roma d'Oriente. Torino.

Roueché, Charlotte M.; Carrié, Jean Michael; Duval, Noël. 2000. "Le De aedificiis de Procope: actes du colloque de Londres: 25-26 septembre 1998. Institute of Classical Studies, Senate house." AntTard 8:9-180.

Roques, D. 1998. "Les constructions de Justinien de Procope de Césarée: document ou monument?" Comptes rendus de l'Académie des Inscriptions et Belles-Lettres 4:989-1001.

Rousseau, Ph. 1998. "Procopius' Buildings and Justinian's Pride." Byzantion 58:121-30. 
Russell, J. C. 1958. "Late Ancient and Mediaeval Population." Trans. of the Am. Philosophical Soc. 48:37-42.

Schneider, A. M. 1936. "Die Vor Justinianische Sophienkirche." Byz. Zeitsch. 36:75-85.

Schneider, A. M. 1941. "Die Grabung in Westhof der Sophienkirche zu Istanbul." IstForsch 12:22-8.

Stefanescu, J. D. 1934. "Sur la mosaique de la Porte Imperiale à Ste-Sophie à Constantinople." Byzantion 9:517-23.

Stein, E. 1949. Histoire du Bas-Empire. Paris-Bruxelles-Amsterdam.

Swift, E. H. 1937. "The Bronze doors of the gate of the Horologium at Hagia Sophia." Art bulletin 19:137-47.

Swift, E. H. 1940. Hagia Sophia. New York.

Turnball, S. 2009. The Walls of Constantinople. A.D. 324-1453. Oxford.

Vespignani, G. 2001. Il circo di Costantinopoli, Nuova Roma. Spoleto.

Webb, R. 2000. "Ekphrasis, amplification and persuasion in Procopius' Builidings." AntTard 8:67-71.

Whitby, M. 2000a. "Procopius' Buildings, Book I: a panegyrical perspective." AntTard 8:45-57.

Whytby, M. 2000b. "Pride and Prejudice in Procopius Buildings: imperial images in Costantinople." AntTard 8:59-66.

\section{*}

Title. The Church of Saint Sophia in Constantinople in the description of Procopius of Cesarea

Abstract. The Saint Sophia Church in Constantinople, wanted by Constantin and restored by the following emperors, was the symbol of the imperial politics of Justinian: destroyed by a fire set to the Senate Palace (532) during the riot "Nika", was reconstituted magnificently by the emperor who wanted to show his triumph against the political adversaries. The Big Church of Justinian must praise the victory of the orthodoxy and attests the greatness of his government. The work De aedificiis Procopius of Cesarea wants to glorify the sovereign- builder, kept by God, through the catalogue of the buildings approved by him in the earthly empire, that intend to show and imitate the sacredness and magnificence of the heavenly reign. He is an intermediary between the humans and God, so his figure is holy, as all whoever connects to him like churches and palaces, and the rebellion that demolished the church was a riot against the faith, he obtained the confirmation of the orthodoxy by his victory on it and showed the sign of the Divine Providence in the magnificence of the new building: God wanted that confirmation to glorify the truth and praise the sovereign chosen by him who defended it. So, taking a special care stressing the use of materials and describing the structure of the church in detail, it seems he wants to stress that these carry to God because they allow to notice, behind the material, symbolical features, and because the contemplation of the beauty turns out a pray of praise. His way of writing is characterized by the accuracy in the description of the features of the church to tell theological and political certain ideas and by the possibility to meet God through the knowledge of the world and of the works wanted by the emperor chosen by him.

Keywords. Procopius of Cesarea; Saint Sophia; Justinian; De aedificiis; Constantinople; Rhetoric; Description. 